Retraction

\title{
Retracted: Leaf Rolling and Stem Fasciation in Grass Pea (Lathyrus sativus L.) Mutant Are Mediated through Glutathione-Dependent Cellular and Metabolic Changes and Associated with a Metabolic Diversion through Cysteine during Phenotypic Reversal
}

\author{
BioMed Research International \\ Received 7 August 2016; Accepted 7 August 2016 \\ Copyright (C) 2016 BioMed Research International. This is an open access article distributed under the Creative Commons \\ Attribution License, which permits unrestricted use, distribution, and reproduction in any medium, provided the original work is \\ properly cited.
}

\begin{abstract}
BioMed Research International has retracted the article titled "Leaf Rolling and Stem Fasciation in Grass Pea (Lathyrus sativus L.) Mutant Are Mediated through GlutathioneDependent Cellular and Metabolic Changes and Associated with a Metabolic Diversion through Cysteine during Phenotypic Reversal" [1]. The article was found to contain images with signs of duplication and manipulation in Figures 1(a), 1(b), 1(d), 2(b), 3(a), 3(b), 3(c), 3(d), 3(k), 4(d), 4(g), 4(m), $4(\mathrm{p}), 8,10(\mathrm{c}), 10(\mathrm{~d}), 10(\mathrm{e}), 10(\mathrm{f}), 10(\mathrm{~g}), 10(\mathrm{~h}), 10(\mathrm{i}), 10(\mathrm{j})$, 10(k), 10(l), and 10(o) and duplication from Talukdar D. An induced glutathione-deficient mutant in grass pea (Lathyrus sativus L.): Modifications in plant morphology, alteration in antioxidant activities and increased sensitivity to cadmium. Biorem. Biodiv Bioavail. 2012; 6: 75-86 in Figure 2B and from Dibyendu Talukdar and Tulika Talukdar, "SuperoxideDismutase Deficient Mutants in Common Beans (Phaseolus vulgaris L.): Genetic Control, Differential Expressions of Isozymes, and Sensitivity to Arsenic," BioMed Research International, vol. 2013, Article ID 782450, 11 pages, 2013, doi: 10.1155/2013/782450 in Figure 10.
\end{abstract}

\section{References}

[1] D. Talukdar and T. Talukdar, "Leaf rolling and stem fasciation in grass pea (Lathyrus sativus 1.) mutant are mediated through glutathione-dependent cellular and metabolic changes and associated with a metabolic diversion through cysteine during phenotypic reversal," BioMed Research International, vol. 2014, Article ID 479180, 21 pages, 2014. 


\title{
Leaf Rolling and Stem Fasciation in Grass Pea (Lathyrus sativus L.) Mutant Are Mediated through Glutathione-Dependent Cellular and Metabolic Changes and Associated with a Metabolic Diversion through Cysteine during Phenotypic Reversal
}

\author{
Dibyendu Talukdar ${ }^{1}$ and Tulika Talukdar ${ }^{2}$ \\ ${ }^{1}$ Department of Botany, R.P.M College, University of Calcutta, Uttarpara, Hooghly, West Bengal 712 258, India \\ ${ }^{2}$ Department of Botany, Acharya Prafulla Chandra Roy Government College, University of North Bengal, Darjeeling, \\ West Bengal 734 010, India \\ Correspondence should be addressed to Dibyendu Talukdar; dibyendutalukdar9@gmail.com \\ Received 25 February 2014; Accepted 24 April 2014; Published 28 May 2014
}

Academic Editor: Pavel Hozak

Copyright (C) 2014 D. Talukdar and T. Talukdar. This is an open access article distributed under the Creative Commons Attribution License, which permits unrestricted use, distribution, and reproduction in any medium, provided the original work is properly cited.

A Lathyrus sativus L. mutant isolated in ethylmethane sulfonate-treated $\mathrm{M}_{2}$ progeny of mother variety BioL-212 and designated as rlfL-1 was characterized by inwardly rolled-leaf and stem and bud fasciations. The mutant exhibited karyomorphological peculiarities in both mitosis and meiosis with origin of aneuploidy. The mitosis was vigorous with high frequency of divisional cells and their quick turnover presumably steered cell proliferations. Significant transcriptional upregulations of cysteine and glutathione synthesis and concomitant stimulations of glutathione-mediated antioxidant defense helped rlfL-1 mutant to maintain balanced reactive oxygen species (ROS) metabolisms, as deduced by ROS-imaging study. Glutathione synthesis was shut down in buthionine sulfoximine- (BSO-) treated mother plant and mutant, and leaf-rolling and stems/buds fasciations in the mutant were reversed, accompanied by normalization of mitotic cell division process. Antioxidant defense was downregulated under low glutathioneredox but cysteine-desulfurations and photorespiratory glycolate oxidase transcripts were markedly overexpressed, preventing cysteine overaccumulation but resulted in excess $\mathrm{H}_{2} \mathrm{O}_{2}$ in BSO-treated mutant. This led to oxidative damage in proliferating cells, manifested by severe necrosis in rolled-leaf and fasciated stems. Results indicated vital role of glutathione in maintaining abnormal proliferations in plant organs, and its deficiency triggered phenotypic reversal through metabolic diversions of cysteine and concomitant cellular and metabolic modulations.

\section{Introduction}

Intracellular thiol redox status is a critical parameter in determining plant growth and development in response to continuous production of reactive oxygen species (ROS) [1]. In aerobic cells, ROS homeostasis is delicately balanced $[2,3]$ and mediates crucial intracellular signaling pathways which are essential for cell survival [3]. However, an excess of ROS formation shifts the redox balance in favor of oxidative state which leads to cell damage and death. The increase of ROS, however, can induce an adaptive response, consisting of a compensatory upregulation of antioxidant systems, aimed to restore the redox homeostasis [3, 4]. Glutathione (reduced form: GSH; oxidized form: GSSG), the tripeptide $\gamma$-glutamylcysteinylglycine, is the principal antioxidant component and predominant form (>90\%) of nonprotein thiol within a cell. In plants, GSH is synthesized enzymatically from its constituent amino acids via two-step ATP-dependent pathway catalyzed by $\gamma$-glutamylcysteine synthetase ( $\gamma$-ECS), the rate-limiting step, and can be inhibited by treating with BSO (L-buthionine sulfoximine) and GSH synthetase (GSHS) [3]. Owing to the presence of a strong nucleophilic thiol group on its cysteine (Cys) residue, GSH interacts with numerous cellular components as an efficient redox buffer, provides valuable information on cellular redox state, and, most importantly, regulates enzymatic processes both upstream of thiol-cascade and downstream of thiol metabolites in order to maintain plant growth and 
maximize cellular defenses against stresses [1, 3]. GSH is an important factor controlling cell proliferations during tumour growth in animal cells [5]. Elevated GSH levels were observed in various types of proliferative response and progression of cell cycle [5]. Moreover, the content of GSH in some tumor cells is typically associated with higher levels of GSH-related enzymes, such as $\gamma$-ECS activities [5]. In plants, GSH is crucial in postembryonic development of the root [6] and the shoot [3], but despite many morphological and biochemical features similar to those found in animal cells, evidence for thiol involvement in plant tumorigenesis is not convincing [7]. GSH plays central role in regeneration of reduced ascorbate from its oxidized form dehydroascorbate (DHA). The resultant glutathione disulfide or GSSG is then recycled to GSH by NADPH-dependent action of glutathione reductase (GR) in ascorbate-GSH cycle [3]. The reduced ascorbate is used as an exclusive cofactor by ascorbate peroxidase during scavenging of $\mathrm{H}_{2} \mathrm{O}_{2}$ [3]. The $\mathrm{H}_{2} \mathrm{O}_{2}$ is one of the prominent diffusible ROS within the cell and is continuously generated in aerobic cells by photorespiration, activity of superoxide dismutase (SOD), and other reasons. Dual roles of $\mathrm{H}_{2} \mathrm{O}_{2}$ as an inducer of oxidative stress and a powerful signaling molecule for antioxidant upregulations have been investigated in crop plants, experiencing biotic and abiotic stresses [8-11]. The conjugation of GSH to heavy metals, herbicides, and xenobiotics is accomplished by multifunctional enzymes glutathione $S$-transferases (GSTs) [12], establishing the now widely accepted role of GSTs as cell housekeepers involved in the detoxification of endogenous as well as exogenous substances. More recently, several GST isoenzymes have been shown to modulate cell signaling pathways that control animal cell proliferation and cell death (apoptosis) [5, 13]. Blockage of the GSH/GST detoxification system enhanced the chemosensitivity of several tumor cell lines. Consequently, excess generation of oxidative intermediates and depletion of GSH have been found to either precede the onset of apoptosis or render the cells more sensitive to death $[5,13]$. Glutathione peroxidases (GPXs) are also involved in removal of organic peroxides and $\mathrm{H}_{2} \mathrm{O}_{2}$ using GSH or thioredoxins as electron donors [3]. The GSH/(GSH + GSSG) ratio, considered as GSH redox state, is likely to be far more influential in the antioxidant defense, controlling gene expressions and thionylation process than the absolute size of the glutathione pool [3].

Cysteine (Cys), one of the vital building blocks of GSH, is the first stable and committed molecule in plant metabolism that contains both sulfur and nitrogen, synthesized by the $\mathrm{O}$-acetylserine (thiol)lyase (OAS-TL) either in free active homodimer or in association with serine acetyltransferase (SAT) as an inactive subunit of the cysteine synthase complex $[1,14]$. OAS-TL is the most enigmatic enzymatic systems in sulfur metabolisms and its isoforms along with SAT in different cellular compartments are under strict regulations in plants responding to environmental stresses $[1,14,15]$. While depleting Cys level escalates the stress sensitivity [1, 15], free Cys, but not GSH, above a certain concentration threshold reportedly has the ability to exacerbate the prooxidant properties due to high reactivity of its thiol moiety $[16,17]$. The opposite mechanisms of Cys biosynthesis and its cellular degradation have immense significance in maintaining Cys homeostasis and this is under tight regulations under stressful environments [16-18]. Studies indicate that Cys degradation is mainly mediated through the desulfuration of L-Cys and D-Cys by L-cysteine desulfhydrase (LCD) and D-cysteine desulfhydrase (DCD), respectively, rather than promoting Cys biosynthesis in high plants [18]. The resultant hydrogen sulfide participates in different physiological activities to promote plant growth processes but can also induce oxidative stress to promote cell death [18-20].

Development of plant organ is highly dynamic and involves the controlled initiation of new primordia from groups of stem cells called meristems. Leaves and the axillary meristems that generate branches and flowers are initiated in regular patterns under tight cellular regulations from the shoot apical meristem (SAM), balancing cell proliferation with the incorporation of cells into new primordia [21]. This balance is essential to maintain SAM integrity and the stereotypical pattern of organ initiation throughout development. Leaf rolling and stem proliferation are two important phenomena in plant developmental process [22-24]; while leaf rolling is supposed to be an adaptation to drought tolerance mechanisms, proliferative growth in stems, buds, and in other plant organs often leads to fasciation through disturbances in SAM. Although moderate leaf rolling and fasciation in plant parts have long been utilized for crop yield enhancement [22], they are still regarded as an enigmatic process as nothing is known regarding intrinsic cellular and biochemical processes involved in cell proliferations during rolling and fasciation. Most of the studies in shoot meristem proliferation have come from mutations in Arabidopsis such as clavata, mgoun1 and mgoun2, fasciata1 and fasciata2, and fully fasciated [23] and in maize [24], revealing involvement of genetic events in the process. To date, 12 rice mutants with rolled leaves have been isolated [22]. However, despite immense importance of leaf rolling and stem fasciation in cell physiological and agronomic point of view and roles of GSH-redox status in regulation of plant growth events, scanty work has been done in this direction [25]. Also, no reports are available regarding cytogenetic behavior of proliferative vegetative and reproductive cells in plants. Grass pea is a very hardy cool-season legume crop, used both for food and feed worldwide. The novelty of this crop in cell biology research has been manifested through development of robust cytogenetic and mutation stocks to decipher the cellular and metabolic events leading to plant growth, development, and stress tolerance [26-28]. Here, we isolated one unique grass pea mutant, exhibiting characteristic leaf-rolling and stem as well as axillary bud fasciation, in $\mathrm{M}_{2}$ progeny of ethylmethane sulfonate- (EMS-) mutagenized population. The mutant was advanced to next generation through self-pollination to perform a detail study. The main goal of the present investigation was to trace the intrinsic cellular and GSHmediated mechanisms behind the phenotypic abnormalities in the mutant plants with the objectives to (1) measure the Cys and GSH pool, (2) investigate the activities and mRNA gene expressions of Cys and GSH biosynthesis and GSH-dependent antioxidant systems, (3) assess the mitotic fidelity and chromosomal anomalies, and (4) detect the ROS 
accumulation and oxidative damage in untreated and BSOtreated tissues of mother variety and mutant line.

\section{Materials and Methods}

2.1. Induction and Detection of Mutants. Fresh seeds of grass pea (Lathyrus sativus L. cv. BioL-212) were collected from Pulses and Oilseed Research Station, Berhampore, West Bengal, India, and grown for two seasons (2010 and 2011) in a private farm at Kalyani $\left(22^{\circ} 59^{\prime} \mathrm{N} / 88^{\circ} 29^{\prime} \mathrm{E}\right)$, West Bengal, India. After ascertaining uniformity of seed age and homozygosity, fresh seeds presoaked in water for $5 \mathrm{~h}$ were treated with freshly prepared $0.15 \%, 0.25 \%$, and $0.5 \%$ aqueous solution of ethylmethane sulfonate (EMS) for $6 \mathrm{~h}$ with intermittent shaking at $25 \pm 2^{\circ} \mathrm{C}$ keeping a control (distilled water). After the stipulated period, seeds were thoroughly washed with running tap water and sown in the field treatment wise (200 seeds treatment ${ }^{-1}$ ) along with untreated seeds as control in triplicate during November 2012 (temperature $20^{\circ} \mathrm{C} / 18^{\circ} \mathrm{C}$, day/night, relative humidity $72 \pm 4 \%$, photoperiod $10 \mathrm{~h}$, irradiance $180-200 \mu \mathrm{mol} \mathrm{m} \mathrm{m}^{-2} \mathrm{~s}^{-1}$ ). Selfed seeds of individual $M_{1}$ plants were harvested separately and were grown in the next season in a randomized block design keeping a distance of $30 \mathrm{~cm}$ between rows and $20 \mathrm{~cm}$ between plants to raise $\mathrm{M}_{2}$ progeny. Standard agronomic practices were followed to grow healthy plant progeny. Phenotypes of about $2000 \mathrm{M}_{2}$ individuals were screened during winter of 2012 and 2013. One plant with characteristic in-rolled leaflets and proliferation in stem and axillary buds has been isolated in $\mathrm{M}_{2}$ progeny of EMS- $(0.25 \%, 6 \mathrm{~h})$ treated population. Seeds ( 42 seeds) of this variant plant were carefully harvested and sown in the next season to raise $\mathrm{M}_{3}$ progeny. The mutant phenotype was true breeding, and based on morphological peculiarities, the mutant was designated as rlfL-1 (Rolled leaflet and fasciated Lathyrus mutant-1). Further biochemical and molecular characterizations of the mutant were performed on these progeny plants.

\subsection{Culture Conditions and BSO Treatment Protocol. Grass} pea seeds obtained from $\mathrm{M}_{3}$ plants of rlfL-1 mutant and its mother variety BioL-212 were surface-sterilized with $70 \%$ ethanol for $2 \mathrm{~min}$, rinsed twice in deionized water, and then placed on water-moistened filter papers at dark to germinate at $25^{\circ} \mathrm{C}$. Germinated seedlings were immediately placed in polythene pots $\left(10\right.$ plants pots $\left.^{-1}\right)$ containing $300 \mathrm{~mL}$ of Hoagland's number 2 nutrient media and were permitted to grow for $10 \mathrm{~d}$. The media were either unsupplemented (control plants) or supplemented (three treatment sets) with $1 \mathrm{mM}$ BSO (L-buthionine sulfoximine, Sigma-Aldrich, Bangalore, India) and the seedlings were allowed to grow for another $5 \mathrm{~d}$. Mother variety and rlfL-1 plants submitted to untreated $(0 \mathrm{mM}$ BSO) condition were used as mother control $(\mathrm{MC})$ and mutant control $(\mathrm{MuC})$, respectively, while those treated with BSO were designated as treated mother (TM) and treated mutant (MuT), respectively. Plants were harvested at $15 \mathrm{~d}$ growth period. The experiment was carried out in a completely randomized block design with three replicates in an environmentally controlled growing chamber under a 14-hour photoperiod, temperature of $28 / 18 \pm 2^{\circ} \mathrm{C}$, relative humidity of $70 \pm 2 \%$, and a photon flux density of $100 \mu \mathrm{mol} \mathrm{m}{ }^{-2} \mathrm{~s}^{-1}$. Shoots and roots were rinsed thoroughly with sterile distilled water and oven-dried at $65^{\circ} \mathrm{C}$ for $72 \mathrm{~h}$ to weigh dry mass.

2.3. Estimation of Glutathione, Cys, and Assay of Thiol Metabolizing Enzymes. Reduced and oxidized forms of glutathione were measured following the methods of Griffith [29]. For enzyme assay, plant tissue (leaves and stems) was homogenized in buffers specific for each enzyme under chilled conditions. The homogenate was squeezed through four layers of cheese cloth and centrifuged at $12,000 \mathrm{~g}$ for $15 \mathrm{~min}$ at $4^{\circ} \mathrm{C}$. The protein content of the supernatant was measured using BSA as standard [30]. Assay of serine acetyltransferase (SAT; EC 2.3.1.30) activity was performed following Blaszczyk et al. [31]. An enzyme unit was considered as the amount of enzyme catalyzing the acetylation of $1 \mathrm{pmol}$ of L-serine per minute. The OAS-TL (EC 2.5.1.47) activity was assayed by measuring the production of L-Cys. Assay was started by the addition of $5 \mu \mathrm{L}$ crude extract $(1 \mu \mathrm{g}$ $\mu \mathrm{L}^{-1}$ total protein in $50 \mathrm{mM}$ phosphate buffer, $\mathrm{pH} 8.0$ ). Reactions were conducted in $50 \mathrm{mM}$ phosphate buffer $(\mathrm{pH}$ 8.0) in the presence of $5 \mathrm{mM}$ dithiotreitol (DTT), $12.5 \mathrm{mM}$ $\mathrm{O}$-acetyl L-serine (OAS), and $4 \mathrm{mM}$ sodium sulfide $\left(\mathrm{Na}_{2} \mathrm{~S}\right)$ in a total volume of $100 \mu \mathrm{L}$ assay mixture and allowed to proceed for $30 \mathrm{~min}$ at $30^{\circ} \mathrm{C}$. The reaction was terminated by the addition of $0.1 \mathrm{~mL}$ of $7.5 \%$ trichloroacetic acid [32]. Cys content was measured spectrophotometrically (PerkinElmer, Lambda 35, Mumbai, India) at $560 \mathrm{~nm}$ following Gaitonde [33]. A blank control with all compounds except OAS was maintained, and the linearity of the assay was checked with 2.5 and $10 \mu \mathrm{L}$ of added crude leaf extract. Assay of $\gamma$-ECS (EC 6.3.2.2) and LCD (EC 4.4.1.1) was done by following Seelig and Meister [34] and Bloem et al. [35], respectively. LCD (EC 4.4.1.1) activity was measured by the release of sulfide from Cys in a total volume of $1 \mathrm{~mL}$ consisting of $2.5 \mathrm{mM}$ dithiothreitol, $0.8 \mathrm{mM}$ L-Cys, $100 \mathrm{mM}$ TRIS/HCl, $\mathrm{pH}$ 9.0, and enzyme extract [35]. The reaction was initiated by the addition of L-Cys. After incubation for $15 \mathrm{~min}$ at $37^{\circ} \mathrm{C}$ the reaction was terminated by adding $100 \mu \mathrm{L}$ of $30 \mathrm{mM} \mathrm{FeCl}_{3}$ dissolved in $1.2 \mathrm{~N} \mathrm{HCl}$ and $100 \mu \mathrm{L}$ of $20 \mathrm{mM} \mathrm{N}, \mathrm{N}$-dimethylp-phenylenediamine dihydrochloride dissolved in $7.2 \mathrm{~N} \mathrm{HCl}$ [35]. The formation of methylene blue was determined at $670 \mathrm{~nm}$. Solutions with different concentrations of $\mathrm{Na}_{2} \mathrm{~S}$ were prepared and treated in the same way as the assay samples and were used for the quantification of enzymatically formed $\mathrm{H}_{2} \mathrm{~S}$. DCD (EC 4.4.1.15) activity was determined in the same way, but D-Cys was used instead of L-Cys [35]. Four samples per treatment were collected with four replications in the assays.

2.4. Assay of Antioxidant Enzymes. Tissue of $250 \mathrm{mg}$ was homogenized in $1 \mathrm{~mL}$ of $50 \mathrm{mM}$ K-phosphate buffer ( $\mathrm{pH}$ 7.8) containing $1 \mathrm{mM}$ EDTA, $1 \mathrm{mM}$ DTT, and $2 \%$ (w/v) polyvinyl pyrrolidone using a chilled mortar and pestle kept in an ice bath. The homogenate was centrifuged at $15,000 \mathrm{~g}$ at $4^{\circ} \mathrm{C}$ for $20 \mathrm{~min}$. Clear supernatant was used for enzyme assays. For measuring APX activity, the tissue was separately ground in 
homogenizing medium containing $2.0 \mathrm{mM}$ AsA in addition to the other ingredients. All assays were done at $25^{\circ} \mathrm{C}$. Soluble protein content was determined using BSA as a standard [30]. SOD (EC 1.15.1.1) activity was determined by the nitroblue tetrazolium (NBT) assay as described by Beyer Jr. and Fridovich [36] and detailed earlier [37]. For ascorbate peroxidase (APX, EC 1.11.1.11) activity, three milliliter of the reaction mixture contained $50 \mathrm{mM}$ potassium phosphate buffer $(\mathrm{pH}$ 7.0), $0.1 \mathrm{mM}$ EDTA, $0.5 \mathrm{mM}$ ascorbate, $0.1 \mathrm{mM} \mathrm{H}_{2} \mathrm{O}_{2}$, and $0.1 \mathrm{~mL}$ enzyme extract. The $\mathrm{H}_{2} \mathrm{O}_{2}$-dependent oxidation of ascorbate was followed by a decrease in the absorbance at $290 \mathrm{~nm}$ (extinction coefficient $2.8 \mathrm{mM}^{-1} \mathrm{~cm}^{-1}$ ). APX activity was expressed as $\mu \mathrm{mol}$ ascorbate oxidized $\mathrm{min}^{-1} \mathrm{mg}^{-1}$ protein [38]. GR (EC 1.6.4.2) activity was determined by monitoring the GSH-dependant oxidation of NADPH, as described by Carlberg and Mannervik [39]. In a cuvette, $0.75 \mathrm{~mL} \mathrm{0.2} \mathrm{M} \mathrm{potassium} \mathrm{phosphate} \mathrm{buffer} \mathrm{(} \mathrm{pH} 7.0$ ) containing $2 \mathrm{mM}$ EDTA, $75 \mu \mathrm{L}$ NADPH $(2 \mathrm{mM})$, and $75 \mu \mathrm{L}$ oxidized glutathione $(20 \mathrm{mM})$ were mixed. Reaction was initiated by adding $0.1 \mathrm{~mL}$ enzyme extract to the cuvette and the decrease in absorbance at $340 \mathrm{~nm}$ was monitored for $2 \mathrm{~min}$. GRspecific activity was expressed as nmol NADPH oxidized $\mathrm{min}^{-1} \mathrm{mg}^{-1}$ protein. GST (EC 2.5.1.18) activity was assayed in a reaction mixture containing $50 \mathrm{mM}$ phosphate buffer, $\mathrm{pH}$ 7.5, $1 \mathrm{mM}$ 1-chloro-2,4-dinitrobenzene (CDNB), and the elute equivalent to $100 \mu \mathrm{g}$ of protein. The reaction was initiated by the addition of $1 \mathrm{mM}$ GSH (Sigma-Aldrich), and formation of S-(2,4-dinitrophenyl) glutathione was monitored as an increase in absorbance at $334 \mathrm{~nm}$ to calculate the GSTspecific activity [40]. Total GPX (EC 1.15.1.1) activity was determined from $1 \mathrm{~g}$ plant tissues extracted in $3 \mathrm{~mL}$ of $0.1 \mathrm{M}$ Tris- $\mathrm{HCl}, \mathrm{pH} 7.5$, containing $2 \mathrm{mM}$ DTT and $1 \mathrm{mM}$ EDTA. The enzyme activity was ascertained by using cumene hydroperoxide (both selenium and nonselenium enzyme types) as a substrate and GR coupled assay to monitor the oxidation of GSH [41]. GPX activity was expressed as change in absorbance at $340 \mathrm{~nm}$. Glycolate oxidase (GO; EC 1.1.3.15) activity was assayed by the formation of a glyoxylatephenylhydrazone complex at $324 \mathrm{~nm}$ [42]. The GO assay mixture contained $100 \mathrm{mM}$ of phosphate buffer ( $\mathrm{pH} 8.3$ ), $40 \mathrm{mM}$ glycolic acid, $100 \mathrm{mM}$ L-Cys, and $100 \mathrm{mM}$ phenylhydrazine. The reaction was started with the addition of the $1 \mathrm{mM}$ FMN, and the absorbance was monitored over $300 \mathrm{~s}$. GO activity was calculated using the molar extinction coefficient of the glyoxylate-phenylhydrazone complex $\left(17 \mathrm{mM}^{-1} \mathrm{~cm}^{-1}\right)$ and was expressed as $\mu \mathrm{mol}$ glyoxylate $\mathrm{min}^{-1} \mathrm{mg}^{-1}$ protein.

2.5. Measurement of Endogenous $\mathrm{H}_{2} \mathrm{~S}$. Endogenous $\mathrm{H}_{2} \mathrm{~S}$ was determined by the formation of methylene blue from dimethyl-p-phenylenediamine in $\mathrm{H}_{2} \mathrm{SO}_{4}[19,43]$, with some modifications. About $0.5 \mathrm{~g}$ of tissues was ground and extracted in $5 \mathrm{~mL}$ of phosphate buffer solution ( $\mathrm{pH} 6.8$, $50 \mathrm{mM}$ ) containing $0.1 \mathrm{M}$ EDTA and $0.2 \mathrm{M}$ ascorbate. The homogenate was mixed with $0.5 \mathrm{~mL}$ of $1 \mathrm{M} \mathrm{HCl}$ in a test tube to release $\mathrm{H}_{2} \mathrm{~S}$, and $\mathrm{H}_{2} \mathrm{~S}$ was absorbed in a $1 \%(\mathrm{w} / \mathrm{v})$ zinc acetate $(0.5 \mathrm{~mL})$ trap, located in the bottom of the test tube. After $30 \mathrm{~min}$ of reaction, $0.3 \mathrm{~mL}$ of $5 \mathrm{mM}$ dimethyl-pphenylenediamine dissolved in $3.5 \mathrm{mM} \mathrm{H}_{2} \mathrm{SO}_{4}$ was added to the trap. Then $0.3 \mathrm{~mL}$ of $50 \mathrm{mM}$ ferric ammonium sulfate in $100 \mathrm{mM} \mathrm{H}_{2} \mathrm{SO}_{4}$ was injected into the trap. Amount of $\mathrm{H}_{2} \mathrm{~S}$ in zinc acetate traps was determined spectrophometrically at $667 \mathrm{~nm}$ after leaving the mixture for $15 \mathrm{~min}$ at room temperature. Blanks were prepared by the same procedures without the zinc acetate solution.

2.6. Determination of $\mathrm{H}_{2} \mathrm{O}_{2}$ Content, Lipid Peroxidation Level, and Electrolyte Leakage \%. Level of $\mathrm{H}_{2} \mathrm{O}_{2}$ was estimated following the methods of Wang et al. [44]. Fresh tissue of $0.1 \mathrm{~g}$ was powdered with liquid nitrogen and blended with $3 \mathrm{~mL}$ acetone for $30 \mathrm{~min}$ at $4^{\circ} \mathrm{C}$. Then the sample was filtered through eight layers of gauze cloth. After addition of $0.15 \mathrm{~g}$ active carbon, the sample was centrifuged twice at 3,000 $\mathrm{g}$ for $20 \mathrm{~min}$ at $4^{\circ} \mathrm{C}$; then $0.2 \mathrm{~mL} 20 \% \mathrm{TiCl}_{4}$ in $\mathrm{HCl}$ and $0.2 \mathrm{~mL}$ ammonia were added to $1 \mathrm{~mL}$ of the supernatant. After reaction, the compound was centrifuged at 3,000 $\mathrm{g}$ for $10 \mathrm{~min}$; the supernatant was discarded and the pellet was dissolved in $3 \mathrm{~mL}$ of $1 \mathrm{M} \mathrm{H}_{2} \mathrm{SO}_{4}$ and absorbance was measured at $410 \mathrm{~nm} . \mathrm{H}_{2} \mathrm{O}_{2}$ content was measured from the absorbance at $410 \mathrm{~nm}$ using a standard curve [44]. Lipid peroxidation was determined by measuring the malondialdehyde (MDA) equivalents while EL\% was assayed following the methods detailed earlier [45].

2.7. Relative Gene Expression Analysis through Quantitative $R T-P C R$. Candidate mRNA gene expression levels of SAT, OAS-TL, $\gamma$-ECS, LCD, DCD, SOD, APX, GR, GSTs, GPX, and $\mathrm{GO}$ of control (MC and $\mathrm{MuC}$ ) and BSO-treated plants (TM and $\mathrm{MuT}$ ) were analyzed by quantitative reverse transcription polymerase chain reaction (qRT-PCR) technique. Total RNA was isolated using the RNA isolation kit (Chromous Biotech, Bangalore, India) and treated with DNaseI (Chromous Biotech, Bangalore, India) at $37^{\circ} \mathrm{C}$ for $30 \mathrm{~min}$. The quality of total RNA samples was determined spectrophotometrically (Perkin-Elmer, Lambda 35, Mumbai, India) from A260/280 ratio and by $1 \%$ agarose gel electrophoresis. First strand cDNA was synthesized from DNA-free intact RNA with oligo-dT primers and with MmuLV reverse transcriptase enzyme kit (Chromous Biotech, Bangalore, India) following manufacturer's instructions. Quantitative RT-PCR of firststrand cDNA was run on ABI Step-One (Applied Biosystems, Foster City, CA, USA) Real-Time PCR machine. Amplification was done in a total reaction volume of $50 \mu \mathrm{L}$, containing template (first-strand cDNA) $2.0 \mu \mathrm{L}$, forward and reverse primer $2.0 \mu \mathrm{L}$ each with $50 \mathrm{nM} \mu \mathrm{L}^{-1}$ concentration, $2 \times$ PCR SYBR green ready mixture (Fast Q-PCR Master Mix Chromous Biotech, India, cat number QCR 05/QCR 06) $25.0 \mu \mathrm{L}$, and DEPC water $19.0 \mu \mathrm{L}$. Primers for selected genes were constructed by Primer Express V. 3.0 software (Applied Biosystems, Foster City, CA, USA) with the search of available sequence databases (http://www.ncbi.nlm.nih.gov) and reports on Phaseolus vulgaris [37], Lens culinaris [15, 46], and Arabidopsis thaliana $[18,47]$. The sequences $\left(5^{\prime} \rightarrow 3^{\prime}\right)$ of forward (F) and reverse (R) primer in each of the candidate genes are presented in Table 1 . The qRT-PCR cycling stages consisted of initial denaturation at $94^{\circ} \mathrm{C}(3 \mathrm{~min})$, followed by 35 cycles of $94^{\circ} \mathrm{C}(5 \mathrm{~s}), 62^{\circ} \mathrm{C}(10 \mathrm{~s}), 72^{\circ} \mathrm{C}(10 \mathrm{~s})$, and a final 
TABLE 1: Oligonucleotide primers used in qRT-PCR analysis of the expression of selected target genes in grass pea (Lathyrus sativus L.) genotypes. F: forward, R: reverse primers.

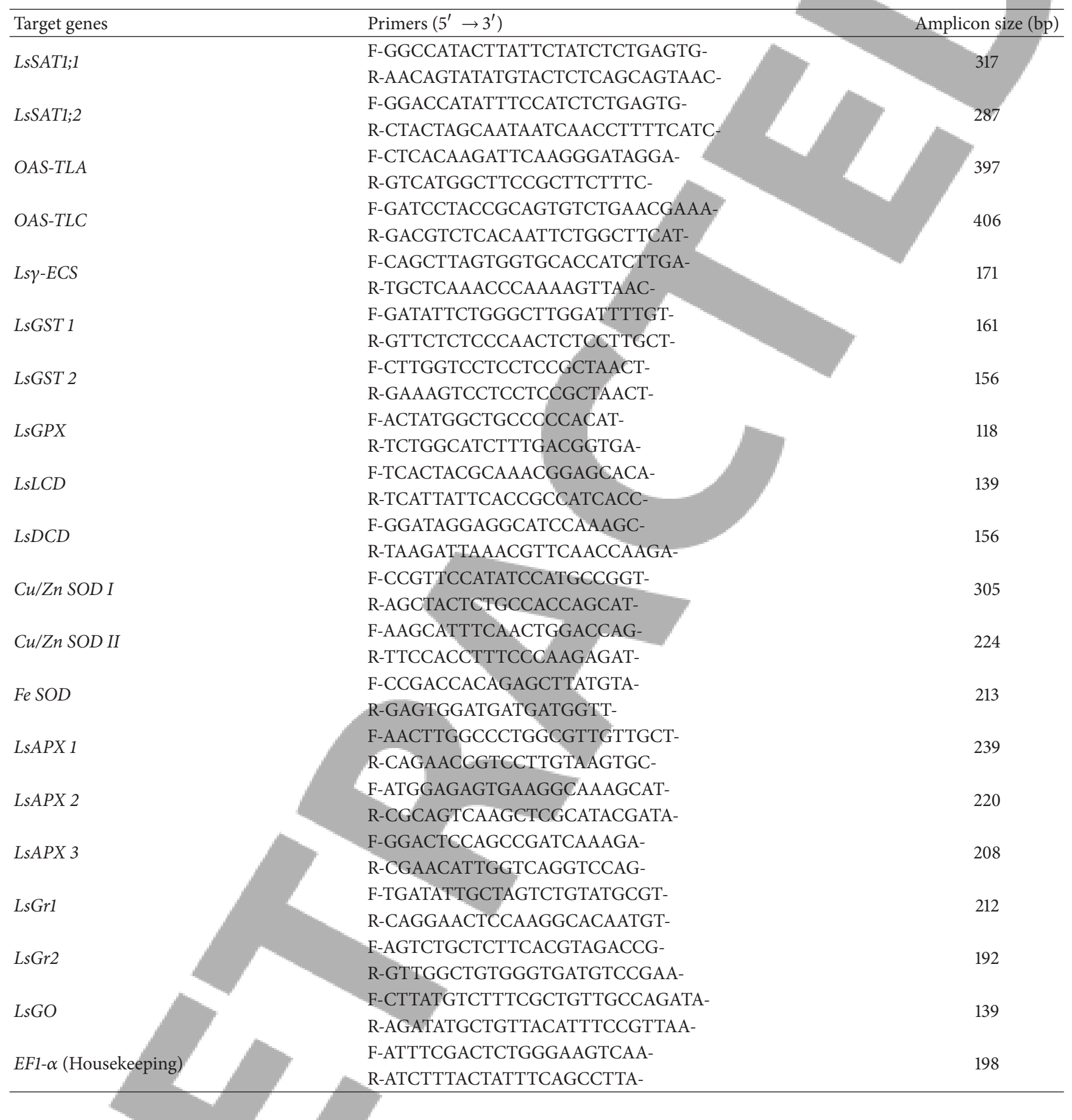

extension stage at $72^{\circ} \mathrm{C}(2 \mathrm{~min})$. A melting curve analysis was performed after every PCR reaction to confirm the accuracy of each amplified product. Samples for qRT-PCR were run in four biological replicates with each biological replicate containing the average of three technical replicates. DEPC water for the replacement of template was used as negative control. RT-PCR reaction mixtures were loaded onto $2 \%$ agarose gels in TAE buffer. A 100-bp DNA ladder was run on every gel. The mRNA levels were normalized against $L$. culinaris EF1- $\alpha$ as the housekeeping gene, and the relative (to control) expression of target genes was calculated as $2^{-\Delta \Delta \mathrm{Ct}}$ (http:// www.Appliedbiosystems.com/support/apptech/\#rtpcr) following Livak and Schmittgen [48].

2.8. Cytogenetic Assay. For mitotic study, leaf tips from growing leaves (rolled as well as normal) were pretreated with $2 \mathrm{mM} 8$-hydroxyquinoline for $2.40 \mathrm{~h}$ at room temperature followed by fixation in $45 \%$ acetic acid for 15 minutes at $4^{\circ} \mathrm{C}$. These were then hydrolyzed in a mixture of 1 N HCL and $45 \%$ 
acetic acid $(2: 1)$ at $60^{\circ} \mathrm{C}$ for $10 \mathrm{~s}$. The leaf tips were stained and squashed in 1\% aceto-orcein [49]. Mitotic index (MI) was determined by counting the number of mitotic cells among the total number of scored cells and expressed in percentage. Mitotic phase distribution was studied by scoring frequencies of prophase, metaphase, anaphase, and telophase from the same slides where MI was calculated. The phase indicesprophase index (PI), metaphase index (MtI), anaphase index (AI), and telophase index (TI) were determined by calculating the number of cells in the respective phase among the number of total dividing cells and expressed as percentage [49]. In order to ascertain the duration of divisional stages, growing leaf tips (from rolled leaves and MC separately) were fixed sequentially one after another with an interval of $15 \mathrm{~min}$ and then were stained and squashed. The fixation time was recorded in each case. Duration of total divisional phases (prophase to telophase) was calculated by scoring particular time of fixation from prophase to telophase. Similarly, duration for particular stage was determined by scoring the fixation times when the respective stages peaked in frequency. Six replicates were maintained for each set. The duration of each mitotic stage can now be calculated using the following equation [50]:

$$
\begin{aligned}
& \text { Duration of mitotic stage } \\
& =\frac{\text { Number of cells in a particular stage }}{\text { Total number of cells }} \times 105 \text { minutes }
\end{aligned}
$$

considering that the duration of mitosis from start to finish (including all four stages) is 105 minutes (8.30-10.15 a.m.) in grass pea (Talukdar, unpublished). For each leaf tip sample, 1000 cells were scored, taking note at which stage the cell was in: prophase, metaphase, anaphase, or telophase. Meiotic analysis was carried out following the procedure employed earlier in grass pea [51]. Briefly, suitable sized flower buds collected separately from each genotype were fixed between 9.00 a.m. and 10.00 a.m. in propionic acid alcohol $(1: 2)$ for $6 \mathrm{~h}$ and then were preserved in $70 \%$ alcohol for future studies. After washing the fixed buds in distilled water, anthers were smeared in $1 \%$ propionocarmine solution to analyze meiosis in the microsporocytes. Photomicrographs were taken from well-scattered plants. Sterility of pollen grains was studied following staining of randomly selected anthers with $1 \%$ acetocarmine solution and expressed as percentage [51].

2.9. Detection and Imaging of Superoxide and $\mathrm{H}_{2} \mathrm{O}_{2}$ Radicals by Confocal Laser Scanning Microscopy. Detection and imaging of superoxide radicals in leaf and stem sections were carried out using the fluorescence probe dihydroethidium (DHE), following the earlier method [37]. Grass pea leaf and stem segments of approximately $30 \mathrm{~mm}^{2}$ were incubated for $1 \mathrm{~h}$ at $25^{\circ} \mathrm{C}$, in darkness, with $10 \mu \mathrm{MDHE}$ prepared in $5 \mathrm{mM}$ Tris- $\mathrm{HCl}$ buffer at $\mathrm{pH} 7.4$, and samples were washed twice with the same buffer for $12 \mathrm{~min}$ each. After washing, leaf sections were embedded in a mixture of $15 \%$ acrylamide-bisacrylamide stock solution, and $100 \mathrm{~mm}$ thick sections, as indicated by the vibratome scale, were cut under $10 \mathrm{mM}$ phosphate-buffered saline (PBS). Sections were then soaked in glycerol: PBS (containing azide) $(1: 1 \mathrm{v} / \mathrm{v}$ ) and mounted in the same medium for examination with a (CLSM) system (Carl Zeiss, LSM 780, Bangalore, India) using standard filters and collection modalities for DHE green fluorescence ( $\lambda$ excitation $488 \mathrm{~nm} ; \lambda$ emission $520 \mathrm{~nm}$ ) and chlorophyll autofluorescence ( $\mathrm{Chl}$ a and b, $\lambda$ excitation 429 and $450 \mathrm{~nm}$, resp.; $\lambda$ emission 650 and $670 \mathrm{~nm}$, resp.) as blue. $\mathrm{H}_{2} \mathrm{O}_{2}$ was detected by incubation with $25 \mu \mathrm{M} 2^{\prime} 7^{\prime}$ dichlorofluorescein diacetate (DCF-DA) (excitation $485 \mathrm{~nm}$, emission $530 \mathrm{~nm}$ ) [37]. Preinfused leaf and stem sections with $1 \mathrm{mM}$ tetramethylpiperidinooxy (TMP), a scavenger of superoxide radicals, and $1 \mathrm{mM}$ ascorbate, a scavenger of $\mathrm{H}_{2} \mathrm{O}_{2}$, served as negative controls.

2.10. Statistical Analysis. The results presented were the mean values \pm standard errors obtained from at least four replicates. Statistical significance of mean values between control and treated seedlings was determined by Students $t$-test (twotailed) using Microsoft Excel tool pack "data analysis" 2007. Multiple comparisons among treatments were performed by ANOVA using software SPSS v. 10.0 (SPS Inc., USA), and means were separated by Duncan's multiple range test. A probability of $P<0.05$ was considered significant.

\section{Results and Discussions}

3.1. Phenotypic and Karyo-Morphological Peculiarities inrlfL-1 Mutant in Untreated and BSO-Treated Experimental Conditions. The rlfL-1 mutant exhibited characteristic inwardly rolled (revolute) leaflet pair in compound leaves of grass pea compared to usual linear-lanceolate leaflet pair in MC plants (Figures 1(a), and 1(b)). The rolling of leaflets started from its terminal part since very early seedling stage (Figures 1(c) and 1(d)) and reached in full rolling at vegetative stage much before the onset of flowering (Figure 1(a)). Leaf rolling has been considered as a morphophysiological adaptation of crop plants for drought/heat stress avoidance mechanisms and diseases and or nutritional deficiency [52]. Leaf rolling is orchestrated through abnormal overdivisions of leaflet cells present in the opposite direction of rolling and/or lower divisional rate of cells situated inside the rolling $[22,53-55]$. In the present mutant, upper surface of leaflets remained outside during rolling. The present mutant is unique in the sense that the seedlings were quite healthy and possessed higher shoot and root dry weight than MC (Table 2) and no dwarfism as well as stress situation was apparent. The MC of the mutant was largely uniform without any type of leaf rolling. In grass pea, inward leaf coiling has been reported in genotypes possessing aneuploid genomes $[26,51]$. Although fasciated stem was reported in grass pea $[56,57]$, occurrence of both rolling and fasciation in a single plant was isolated for the first time in a diploid genotype of grass pea.

Leaf rolling in $r l f L-1$ mutant was intimately associated with appearance of stem and axillary bud fasciation in the present investigation (Figures 2(a) and 2(b)). Fasciation resulting from proliferative growth has been explored as a 

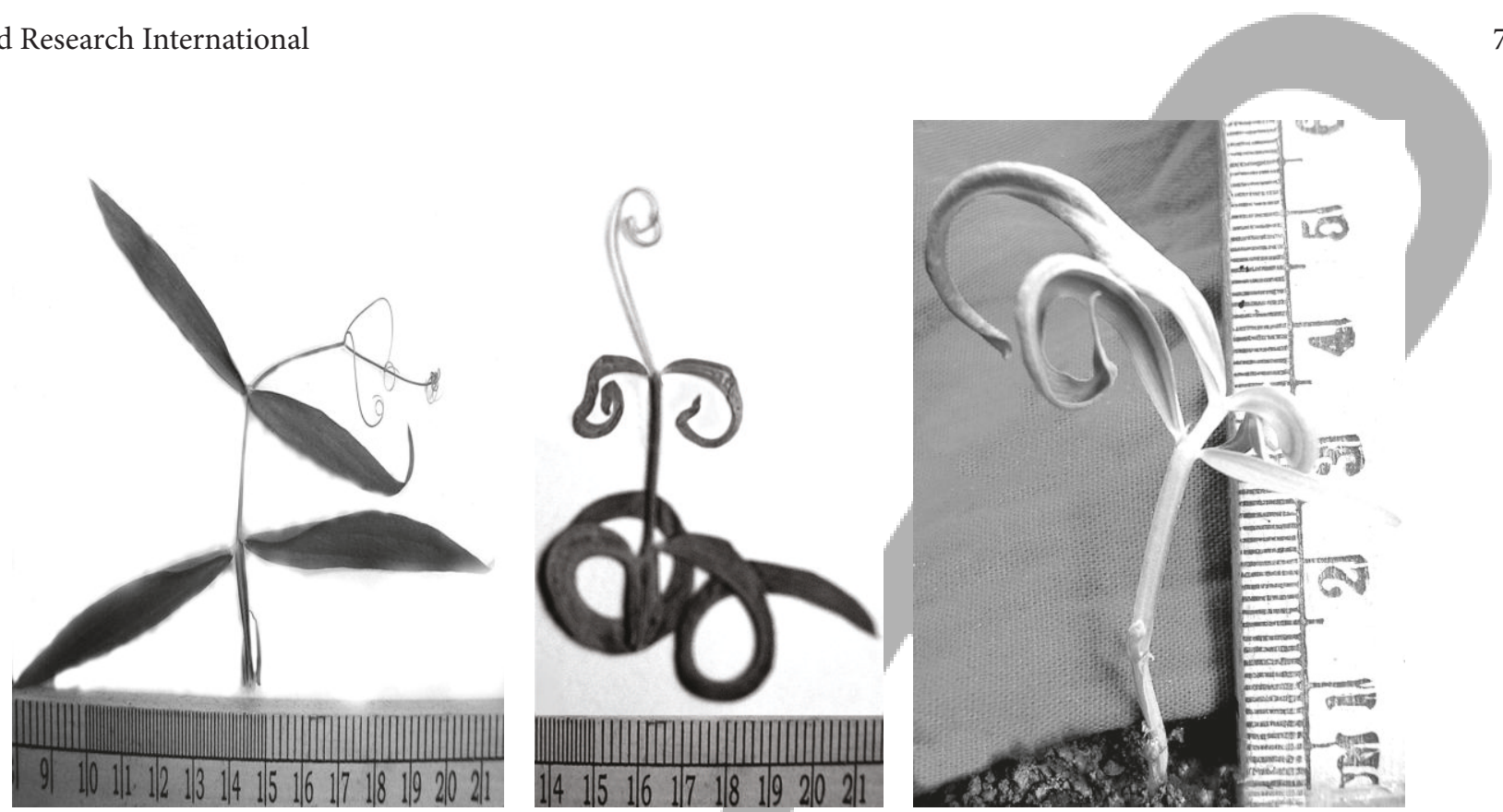

(a)

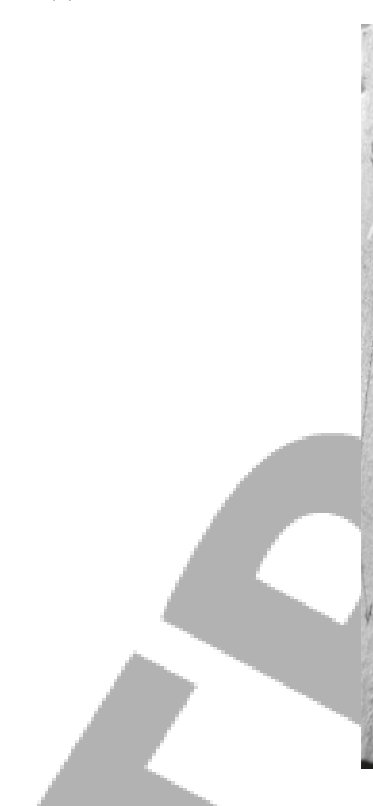

(d) (b)

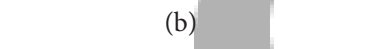

(c)

(c)

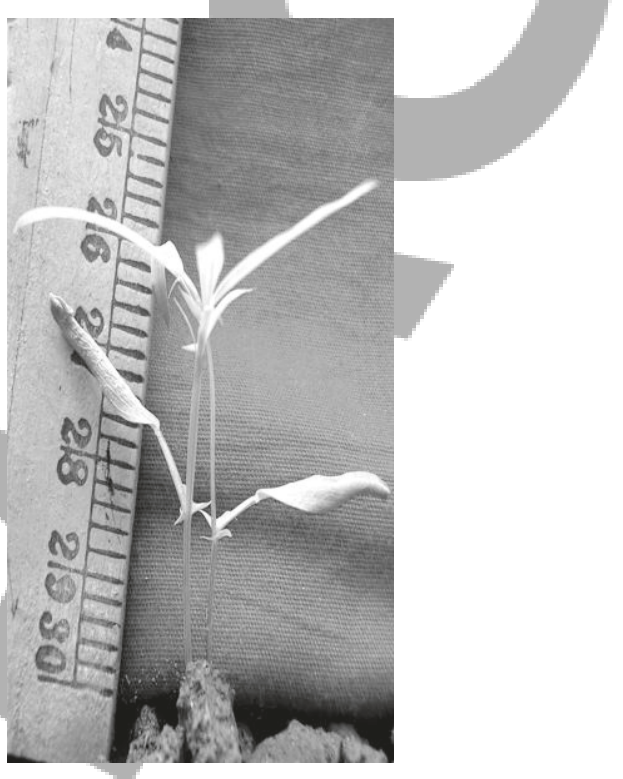

FIGURE 1: (a) Normal linear-lanceolate leaflets in a compound leaf of mother variety BioL-212, (b) inwardly leaf rolling in rlfL-1 mutant, (c) commencement of leaf rolling in rlfL-1 mutant, and (d) initiation of normal leaflet in mother variety BioL-212 at early seedling stage.

SAM mutant in plants [21-23]. Among food legumes, stem fasciation was successfully induced by mutagenic techniques in grass pea [56, 57], chickpea [58], soybean [59], lentil, pea, and other plants [60]. In the present case, overgrowth of stem tissue was observed sporadically in association with proliferation in axillary buds. The buds were drooping from axis of the mutant plants (Figure 2(b)). The occurrence of fasciated portions was, however, not uniformly distributed in stems of rlfL-1 mutant. Importantly, not all leaflets in the mutant were rolled, nor all the axillary buds carried proliferations. Significantly, stem and bud proliferation was noticed in those regions where adjacent leaflet pairs were rolling (Figure 2(b)), and nearly $80 \%$ of total leaflets were found rolled. The proliferated buds in rlfL-1 mutant often developed larger-sized pods with bolder seed and higher 100 seed weight compared to MC. However, the number of seeds per pod reduced (Table 2). Productions of larger-sized seeds are of great commercial importance in legume breeding [61] and suggest partial beneficial effect of present $r l f L-1$ mutant in grass pea.

The rlfL-1 mutant showed cytological peculiarities, as manifested in rolled leaf-tip mitosis and fasciated flower bud meiosis. Compared to 14 chromosomes uniformly distributed in diploid genomes of MC plant and also in normal (MC-like) 


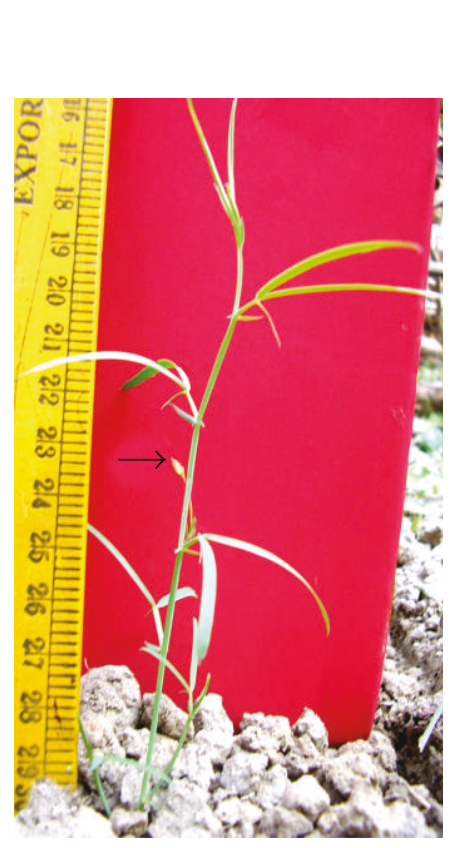

(a)

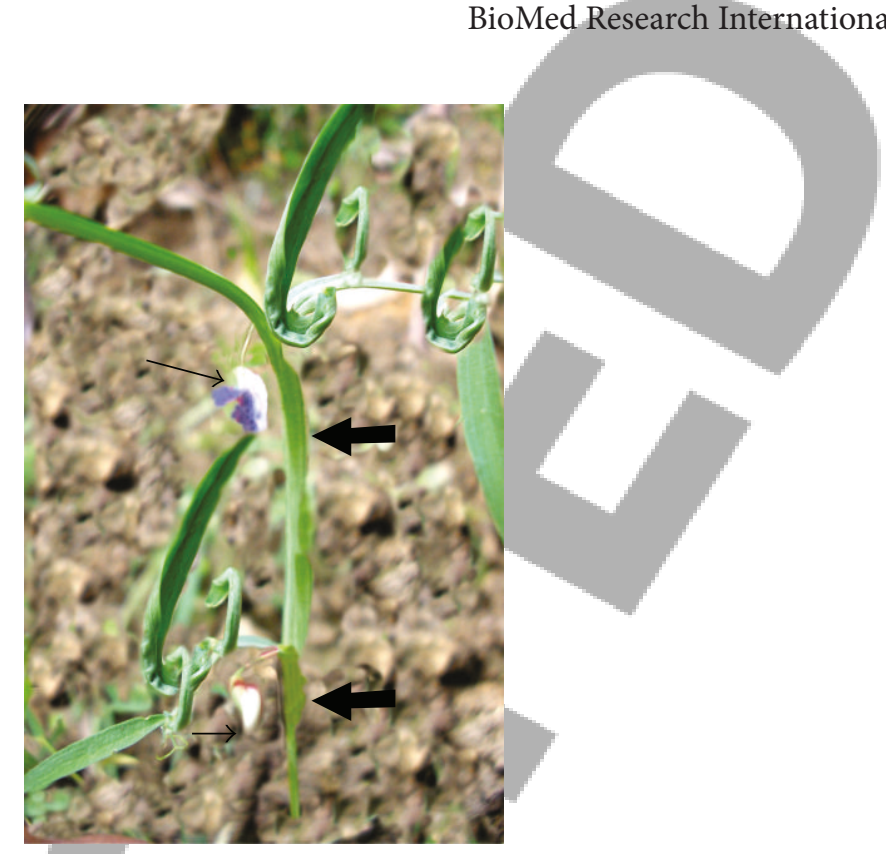

(b)

FIgURe 2: (a) Mother plant BioL-212 with flower bud $(\rightarrow$ ) and nonfasciated stem, (b) mutant $r$ lfL-1 with rolled leaflet, fasciated stem (thick arrow), and fasciated drooping buds (thin arrow) in field condition.

TABLE 2: Phenotypic characteristics, cytological peculiarities, and biochemical features in $r l f L-1$ mutant and its mother variety Biol-212 under untreated and BSO-treated conditions. MC-untreated (no BSO) mother control, MuC-untreated (no BSO), MuT-BSO-treated mutant, and TM-BSO treated mother plant.

\begin{tabular}{|c|c|c|c|c|}
\hline Traits & $\mathrm{MC}$ & $\mathrm{MuC}$ & $\mathrm{MuT}$ & TM \\
\hline Shoot dry weight (g plant ${ }^{-1}$ ) & $0.16 \pm 0.02^{b}$ & $0.29 \pm 0.03^{\mathrm{a}}$ & $0.10 \pm 0.02^{c}$ & $0.07 \pm 0.008^{c}$ \\
\hline Root dry weight (g plant ${ }^{-1}$ ) & $0.19 \pm 0.03^{\mathrm{b}}$ & $0.34 \pm 0.03^{\mathrm{a}}$ & $0.12 \pm 0.04^{\mathrm{b}}$ & $0.06 \pm 0.007^{\mathrm{c}}$ \\
\hline Pod length $(\mathrm{cm})$ & $3.38 \pm 0.35^{\mathrm{b}}$ & $5.87 \pm 0.49^{\mathrm{a}}$ & $3.41 \pm 0.39^{\mathrm{b}}$ & $1.21 \pm 0.12^{\mathrm{c}}$ \\
\hline 100 seed weight $(\mathrm{g})$ & $5.85 \pm 0.43^{b}$ & $11.85 \pm 0.53^{\mathrm{a}}$ & $5.90 \pm 0.44^{\mathrm{b}}$ & $2.37 \pm 0.37^{\mathfrak{c}}$ \\
\hline Seeds pod ${ }^{-1}$ & $3.56 \pm 0.13^{\mathrm{a}}$ & $3.07 \pm 0.11^{\mathrm{a}}$ & $1.15 \pm 0.09^{\mathrm{b}}$ & $1.21 \pm 0.13^{\mathrm{b}}$ \\
\hline Pollen sterility (\%) & $1.33 \pm 0.32^{c}$ & $43.11 \pm 0.53^{\mathrm{b}}$ & $45.51 \pm 0.61^{\mathrm{b}}$ & $63.77 \pm 0.71^{\mathrm{a}}$ \\
\hline MI\% & $15.51 \pm 0.56^{\mathrm{b}}$ & $61.05 \pm 0.77^{\mathrm{a}}$ & $15.63 \pm 0.61^{\mathrm{b}}$ & $7.56 \pm 0.19^{c}$ \\
\hline PI\% & $70.33 \pm 0.67^{\mathrm{b}}$ & $2.53 \pm 0.11^{\mathrm{c}}$ & $66.67 \pm 0.57^{\mathrm{b}}$ & $80.93 \pm 0.67^{\mathrm{a}}$ \\
\hline MtI\% & $17.97 \pm 0.32^{\mathrm{b}}$ & $51.17 \pm 0.45^{\mathrm{a}}$ & $18.63 \pm 0.32^{\mathrm{b}}$ & $7.37 \pm 0.32^{c}$ \\
\hline $\mathrm{AI} \%$ & $8.69 \pm 0.11^{b}$ & $31.30 \pm 0.39^{\mathrm{a}}$ & $10.69 \pm 0.11^{\mathrm{b}}$ & $7.09 \pm 0.11^{c}$ \\
\hline TI\% & $3.01 \pm 0.10^{\mathrm{b}}$ & $13.00 \pm 0.17^{\mathrm{a}}$ & $4.01 \pm 0.10^{\mathrm{b}}$ & $4.61 \pm 0.10^{\mathrm{b}}$ \\
\hline Cysteine content ( $\mathrm{nmoL} \mathrm{g}^{-1} \mathrm{FW}$ ) leaf & $7.43 \pm 0.54^{\mathrm{b}}$ & $9.19 \pm 0.54^{\mathrm{b}}$ & $7.51 \pm 0.59^{b}$ & $33.89 \pm 0.67^{\mathrm{a}}$ \\
\hline Cysteine content (nmoL g $\left.{ }^{-1} \mathrm{FW}\right)$ stems & $6.89 \pm 0.33^{b}$ & $7.03 \pm 0.34^{b}$ & $6.77 \pm 0.59^{\mathrm{b}}$ & $29.76 \pm 0.63^{\mathrm{a}}$ \\
\hline GSH (nmoL g $\left.{ }^{-1} \mathrm{FW}\right)$ leaf & $73.5 \pm 4.8^{\mathrm{b}}$ & $257.8 \pm 7.7^{\mathrm{a}}$ & $1.93 \pm 0.09^{c}$ & $1.87 \pm 0.11^{\mathrm{c}}$ \\
\hline GSSG (nmoL g $\left.{ }^{-1} \mathrm{FW}\right)$ leaf & $11.7 \pm 1.1^{\mathrm{c}}$ & $12.9 \pm 2.1^{\mathrm{c}}$ & $222.8 \pm 6.3^{\mathrm{b}}$ & $228.3 \pm 4.1^{\mathrm{a}}$ \\
\hline GSH redox-leaf $(\mathrm{GSH} /(\mathrm{GSH}+\mathrm{GSSG}))$ & $0.863 \pm 0.07^{\mathrm{b}}$ & $0.954 \pm 0.08^{\mathrm{a}}$ & $0.008 \pm 0.00^{c}$ & $0.008 \pm 0.00^{c}$ \\
\hline GSH (nmoL g ${ }^{-1}$ FW) stems & $70.5 \pm 4.3^{\mathrm{b}}$ & $247.9 \pm 7.9^{\mathrm{a}}$ & $1.95 \pm 0.09^{c}$ & $1.90 \pm 0.11^{\mathrm{c}}$ \\
\hline GSSG (nmoL g $\left.{ }^{-1} \mathrm{FW}\right)$ stems & $12.7 \pm 1.1^{\mathrm{b}}$ & $12.8 \pm 2.1^{\mathrm{b}}$ & $225.9 \pm 6.6^{\mathrm{a}}$ & $230.3 \pm 4.7^{\mathrm{a}}$ \\
\hline GSH redox-stems $(\mathrm{GSH} /(\mathrm{GSH}+\mathrm{GSSG}))$ & $0.847 \pm 0.09^{\mathrm{b}}$ & $0.951 \pm 0.09^{\mathrm{a}}$ & $0.008 \pm 0.00^{c}$ & $0.008 \pm 0.00^{c}$ \\
\hline
\end{tabular}

Data are means \pm SE of at least four replicates. Means followed by same alphabets are not significantly $(P>0.05)$ different at ANOVA followed by Duncan's multiple range test. MI: mitotic index, PI: prophase index, MtI: metaphase index, AI: anaphase index, TI: telophase index, GSH: reduced glutathione, and GSSG: glutathione disulfide.

linear-lanceolate leaflet tip (Figure 3(a)), chromosomes were largely anomalous in rolled leaf-tip of the mutant. The abnormal behavior was characterized by the presence of fragmented chromosomes, unoriented chromosomes, C-mitosis, multipolarity, sticky metaphase, cytomixis, anaphase bridge with or without laggard, broken bridge, diagonal orientations of chromosomes, and aneuploid cells (Figures 3(b)-3(1)). The aneuploid cells were largely trisomics $(2 n=2 x+1=$ 15) or double trisomics $(2 n=2 x+1+1=16)$ and often unoriented during mitotic metaphase (Figure $3(\mathrm{~g})$ ). In meiosis of fasciated bud, nearly $42 \%$ of total pollen mother cells (PMCs) exhibited usual pairing of seven bivalents (7 II) 


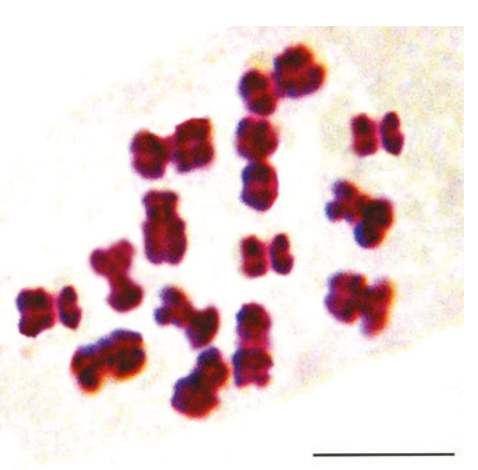

(a)

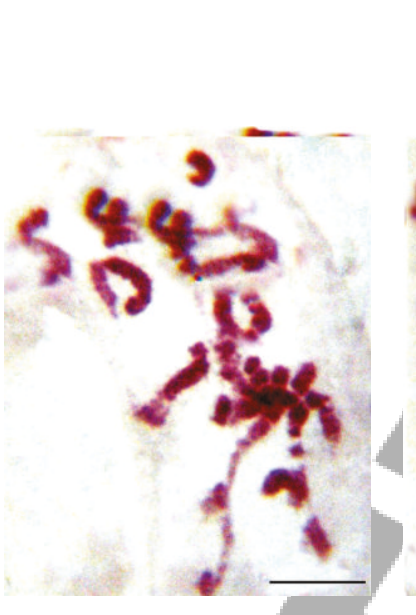

(b)

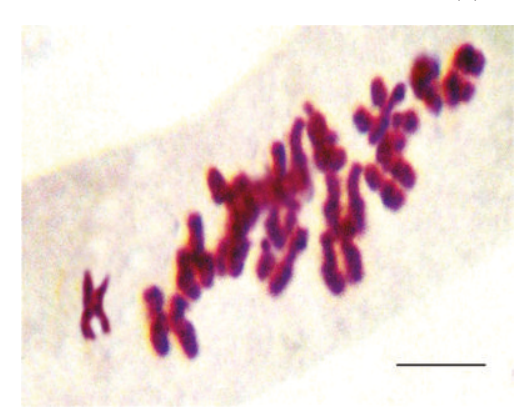

(d)

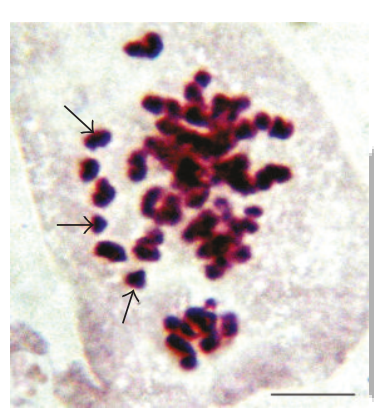

(e)

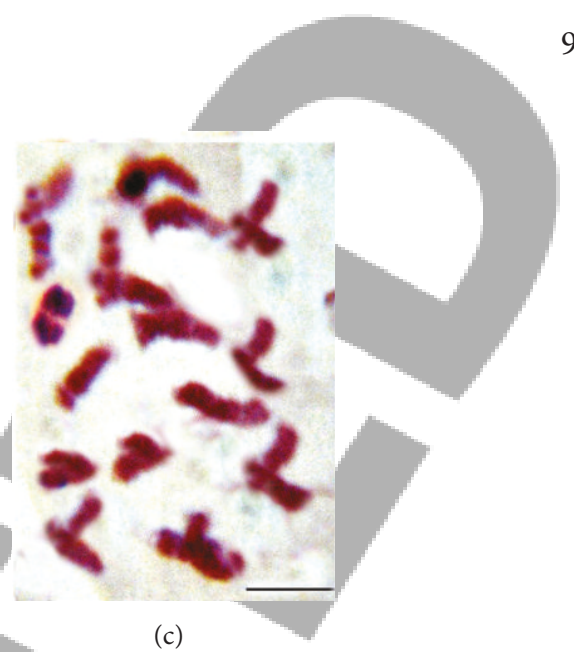

(c)

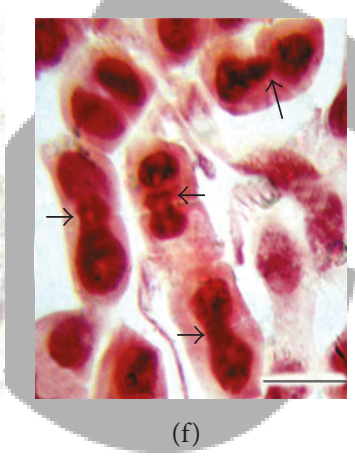

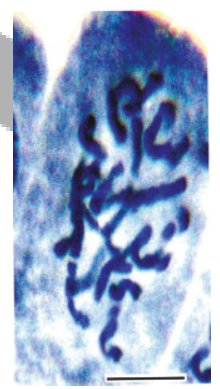

(g)

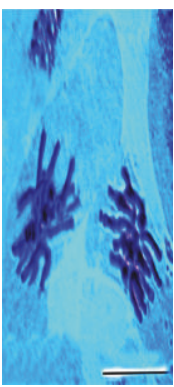

(h)
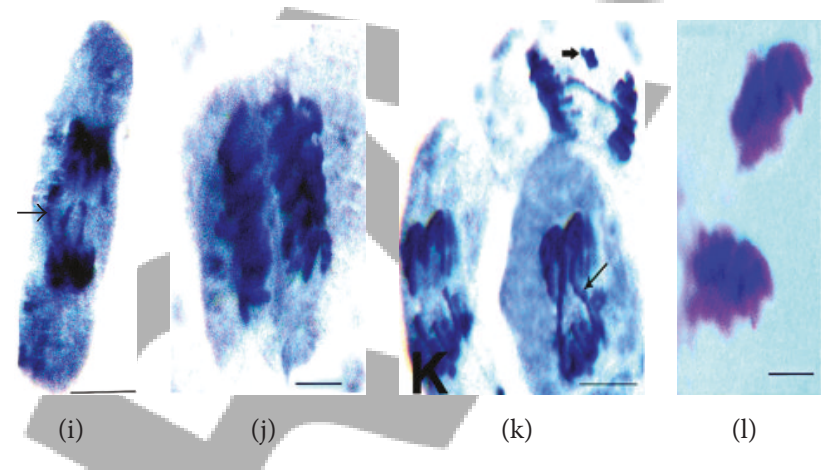

(1)

FIgURE 3: (a) Normal $2 n=2 x=14$ chromosomes in leaf-tip cells of mother variety BioL-212, (b) unoriented abnormal metaphase, (c) aneuploid cells with $2 n=2 x+1=15$ chromosomes, (d) C-mitosis, (e) C-mitotic chromosomes undergoing breakage, (f) mitotic cytomixis, (g) unoriented aneuploid metaphase, (h) sticky metaphase, (i) anaphase bridge broken, (j) anaphase delayed, (k) anaphase bridge with or without laggard $(\rightarrow)$, and (l) diagonal orientation at late anaphase in dividing leaf-tip cells of $r l f L-1$ mutant. Bar represents 1 SD $=10 \mu \mathrm{m}$.

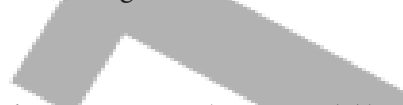

with $2 n=2 x=14$ chromosomes (Figure $4(\mathrm{a})$ ). The rest of the cells were aberrant due to presence of multivalent, univalents, unequal separation of anaphase chromosomes, bridges and lagging chromosomes, micronucleus formations, and aneuploids (Figures 4(b)-4(p)). Multinucleolate conditions accompanied with long retention of nucleoli even at anaphase I were also encountered sporadically (Figures 4(c) and 4(d)). The nucleolus is the major centre of controlling protein synthesis, and thus origin of more than one nucleolus and its retention by dividing cells indicates enhanced protein synthesizing capacity required in the fasciated buds. The results agreed well with occurrence of more than one nucleolus per cell in tumorous HNO (habituated nonorganogenic) cell lines of sugar beet, and the polynucleolation has been regarded as a representative feature of very high rate of cellular metabolism, often observed in cancerous cells
[7]. The extra chromosomes in trisomics were either in univalent or in trivalents (Figures 4(g), 4(i), 4(j), and 4(l)). Occurrence of " $\mathrm{Y}$ "-shaped, frying pan shaped, or rodshaped trivalents at meiotic metaphase indicated origin of primary trisomics while pentavalent formation at meiosis I suggested existence of trisomic genomes with interchanged chromosomes (Figures 4(f) and 4(l)). Occurrence of diagonal orientation, chromosome stickiness, multipolarity, and unorientation of metaphase chromosomes suggested spindle disturbances in dividing cells both in vegetative and reproductive tissues undergoing abnormal proliferations in rlfL-1 mutant. Variations in chromosome number accompanied with diverse types of karyological aberrations like aneuploidy, asynapsis, desynapsis, translocation, fragmented chromosomes, univalents, and anaphase bridges, were observed in Haplopappus gracilis, crown-gall 


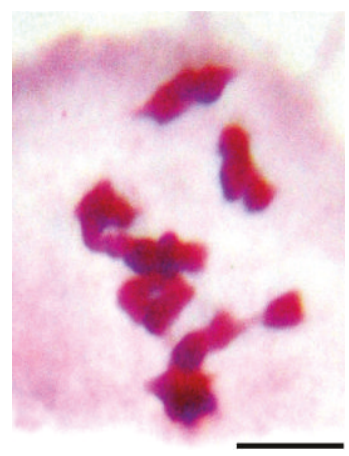

(a)

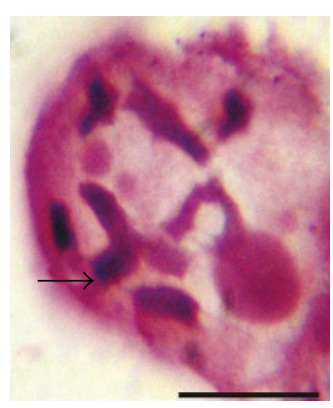

(f)

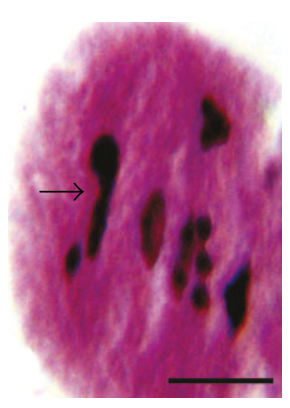

(k)

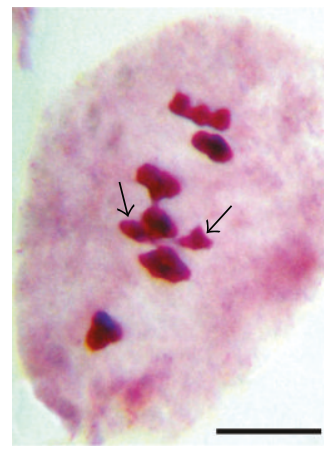

(b)

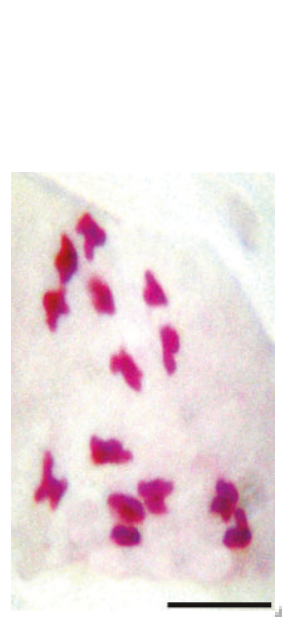

(c)

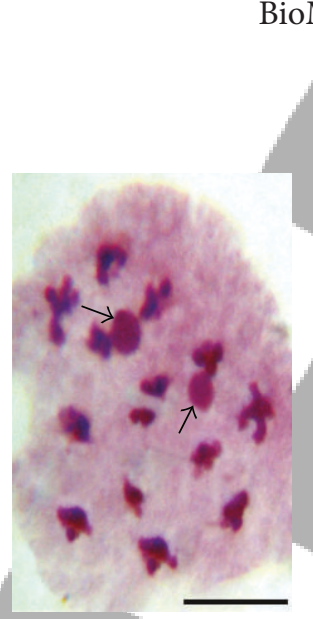

(d)

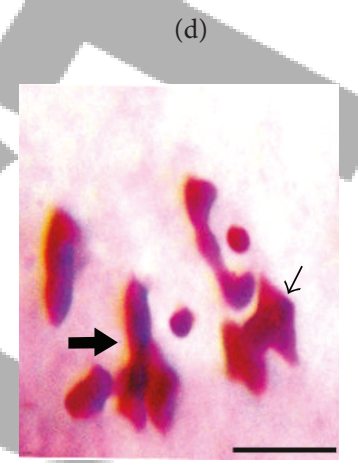

(i)

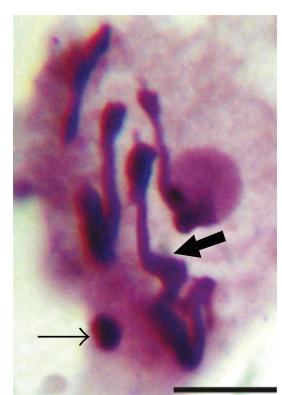

(g)

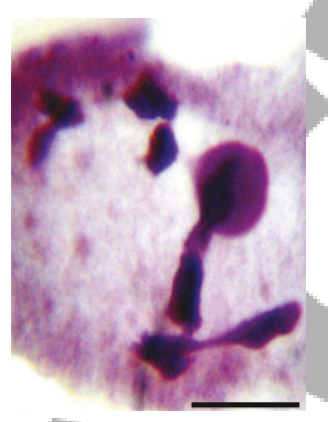

(h)
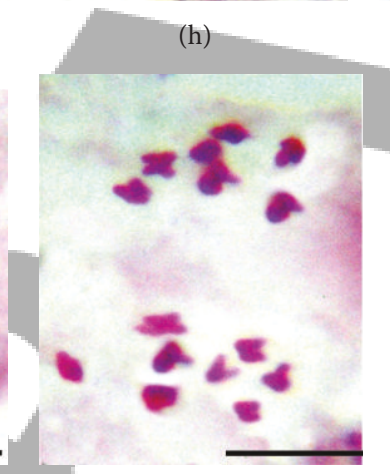

(m)

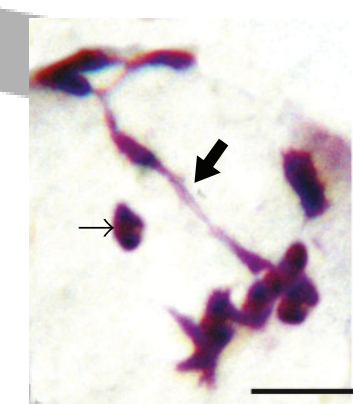

(n)

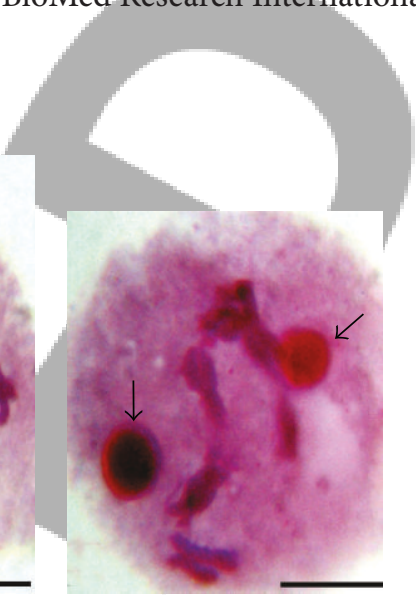

(e)

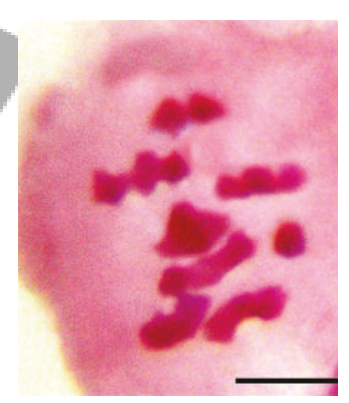

(j)

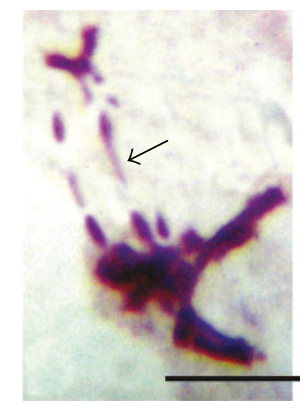

(o)

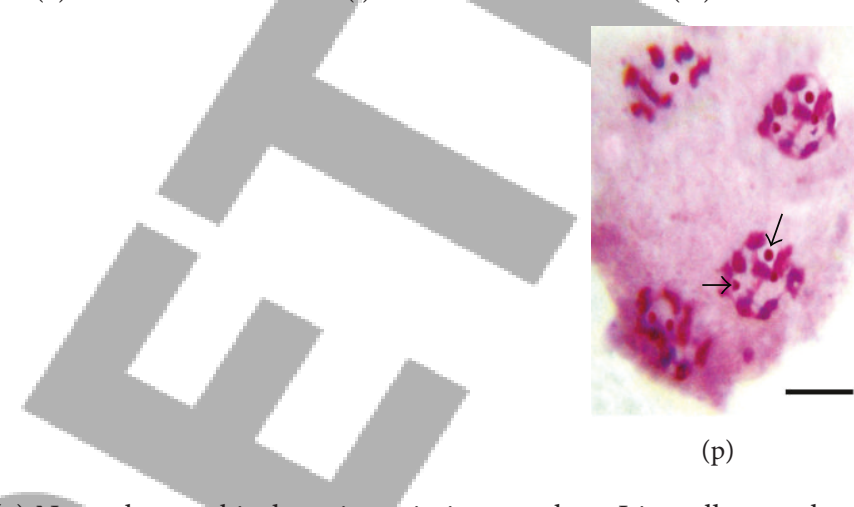

Figure 4: (a) Normal seven bivalents in meiotic metaphase I in pollen mother cells of mother variety BioL-212, (b) six bivalents and two univalents $(\rightarrow$ ) at metaphase I, (c) unoriented 14 chromosomes at anaphase I, (d) long retention of double nucleoli $(\rightarrow)$ at anaphase I, (e) double nucleoli at diakinesis $(\rightarrow)$, (f) "Y"-shaped trivalents $(\rightarrow)$ in trisomic diakinesis, $(\mathrm{g})$ one pentavalent (thick arrow) and one univalent (thin arrow) in trisomic diakinesis, (h) two trivalents $(\rightarrow)$ and three bivalents in diploid diakinesis, (i) one quadrivalent (thin arrow) and one trivalent (thick arrow), two univalents and three bivalents in a trisomic metaphase $\mathrm{I}$, (j) seven bivalents and one univalent in trisomic metaphase I, $(\mathrm{k})$ one trivalent $(\rightarrow)$, one univalent, and five bivalents in diploid metaphase I, $(\mathrm{l})$ one rod-shaped trivalent (thin arrow), two univalents (thick arrow), and five bivalents in a trisomic metaphase I, (m) unequal 8-7 chromosome separation at anaphase I, (n) anaphase bridge with lagging chromosome $(\rightarrow)$, (o) broken anaphase bridge $(\rightarrow)$, (p) micronuclei $(\rightarrow)$ at telophase II in pollen mother cells of fasciated buds of rlfL-1 mutant. Bar represents $1 \mathrm{SD}=10 \mu \mathrm{m}$. 
callus of Nicotiana tabacum, hormone-induced tissue of Pisum sativum, Lotus corniculatus, Avena sativa, rice, wheat, and many other plant species [62]. Obviously, anomalous chromosomal associations in meiosis of PMCs resulted in reduction of pollen fertility (43.11\%) in proliferated buds but it was still enough to maintain self-fertility of the mutant. In animal cells, aberrant cells are often found in tumor cells and occurrence of fragmented and lagging chromosomes as also observed in the present investigation indicates the risk of aneuploidy and further aberrations [63]. Aneuploidy causes a proliferative disadvantage in all normal cells studied so far; yet this condition is associated with unabated proliferative potential [63]. Occurrence of substantial number of trisomic and double trisomic cells in the present rlfL-1 mutant suggested origin of extra chromosomes in the diploid complement, bringing about further disturbances in mitosis and meiosis. Furthermore, due to wasteful transcription, translation, and degradation of proteins encoded by extra chromosomes in trisomic genomes and dosage-effects, aneuploidy dramatically increases cell's energy needs and altered metabolisms often generates excess ROS [64]. Although, these factors are generally believed to lower the proliferative capacity of aneuploid cells, in present case, these disturbances were well tolerated by proliferating cells. Furthermore, origin of trisomic genomes with both primary and tertiary chromosomes strongly indicated presence of both numerical and structural chromosomal aberrations in pollen mother cells of fasciated bud. Quite remarkably, the percentage of rolled leaf with cytological anomaly including aneuploidy increased gradually and fasciated portions invaded some new regions of stem surface following onset of flowering. This indicated some degree of added proliferation in which new regions are being affected during reproductive growth, although it is generally known that unlike animal cells plant cells cannot metastasize. Presumably, EMS-treatment induced mutations that tolerated huge cytological anomalies as well as aneuploid load and improved the fitness of multiple different aneuploidies, as advocated in budding yeast and animal tumor cells [63-65]. Induction of aneuploidy is a strong indication of cancerous growth of cells, as revealed in plant HNO cell line and also in animal cancer cell lines [5, 7]. Under influence from biotic and abiotic factors excessive multiplication of cells can lead to new plant tumor, as revealed by plant crown gall tumorigenesis [66]. Obviously, mutagenesis acted as an inducer of leaf rolling and stem as well as bud proliferations in the present $r l f L-1$ mutant but whether this proliferation represents neoplastic progression in the present mutant, studies on organogenic totipotency are necessary to ascertain it.

Upon imposition of BSO treatment, significant reversals of mutant traits were noticed. Percentage of rolledleaf phenotype and stem fasciation reduced to $1 \%$ at seedling stages and disappeared during flowering stages (Figures 5(a) and 5(b)). Bud fasciation was conspicuously absent in MuT plants (Figure 5(a)). However, premature leaf senescence coupled with necrotic spots on leaf and stem surface and significant reduction in shoot as well as root dry weight occurred in BSO-treated mutant and TM plants (Table 2; Figure 5(a)) but the damage was more pronounced in TM plants (Figure 6). Presumably,
BSO-treatment inhibited tissue proliferation in the mutant plant but at the same time induced necrosis. Necrosis has been considered as initiation of death of cells and tissues and has been reported in Crown-gall tumor tissue of grapes, maize, cauliflower, and in Arabidopsis [67]. Typical cancer cells show susceptibility to necrosis [7]. In the present study, cell death through necrosis might be a defense mechanism of the mutant plant to suppress the proliferated tissues, as has been explained in crown-gall necrosis in different plants [67] and necrosis induced by environmental carcinogen, mutagen, virus infections, and heavy metal stress $[37,68]$.

3.2. Mitotic Fidelity in rlfL-1 Mutant. Mitotic index (MI), duration, and transition of divisional phases are the important features of mitotic fidelity and cellular fitness [50]. Number of dividing cells and rate of cell divisions determine the rate of cell production by a meristem [21]. MI in the rolled leaf-tip of the mutant was scored fourfold higher in comparison to MC plants (Table 2). This indicated differential cellular response of proliferated cells and nonproliferated cells. This observation was further substantiated by the sharp differences in transition of divisional phases, determined by phase indices between MC and mutant leaf-tip cells. Results in Table 2 revealed that PI value was greatly reduced while MtI, AI, and TI values increased over MC values by about 34 -fold in the rolled-leaf tips (Table 2). The results suggested that most of the cells in growing tip of rolled leaflet rapidly entered into next phase of divisions to complete the divisions, and obviously, high MI values in mutant plants might be attributed to high frequency of cells passing through these three stages. Quite alarmingly, most of the chromosomally aberrant cells in rolled leaf tips were scored in metaphase and anaphase stages, and high TI values confirmed that the dividing cells in rolled leaf tip successfully completed their divisional cycle. Duration of each phase also deviated sharply in the mutant plants from those observed in MC plants. The periodicity of divisional phases was ascertained through timewise monitoring of duration of four mitotic phases through simple fixation procedure standardized for the grass pea genotypes (Talukdar, unpublished). Total duration (prophase to telophase) was estimated to be $105 \mathrm{~min}$ considering peak period of particular stage in MC plants (Figure 7). Contrastingly, mean duration of total divisional phases reduced by about 2.5 -fold in the mutant plants (Figure 7). Although duration of prophase and telophase changed marginally, compared to MC, peak metaphase and anaphase duration in the mutant reduced by about 3 -fold and 2-fold, respectively (Figure 7), resulting in sharp decline of phase duration in rolled leaf mitotic stage. The shortening of divisional duration might be due to necessity of the mutant for a quick turnover of cell division process and carrying over high number of dividing cells (high MtI and AI values) in the next division cycle. However, this carries the high risk of newly formed aberrant cells including aneuploidy in growing leaf tips.

Dramatic turnover of mitotic events in mutant and MC plants was observed once the BSO was added in the medium. Compared to $\mathrm{MuC}$, MI values reduced significantly and 


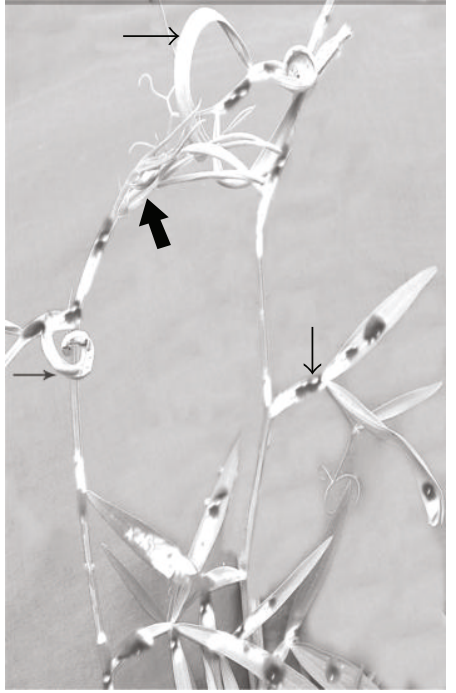

(a)

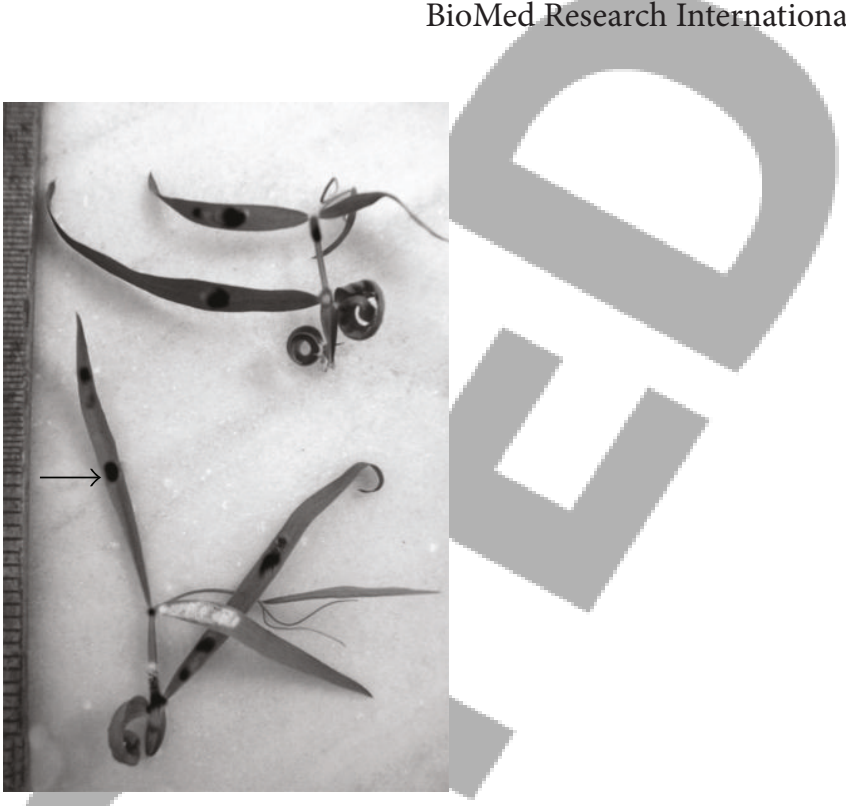

(b)

FIGURE 5: (a) and (b) Reversal of leaf rolling and stem as well as bud fasciation $(\rightarrow$ ) accompanied with occurrence of necrosis and yellowing of leaves $(\rightarrow)$ in BSO-treated rlfL-1 mutant of grass pea.

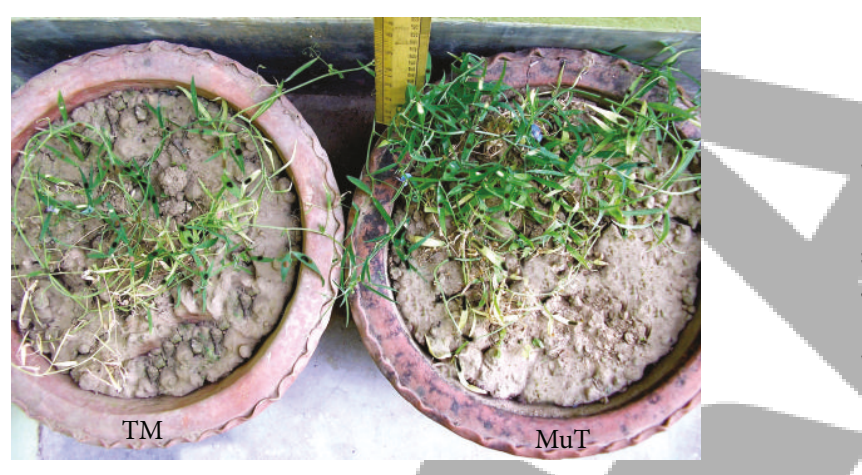

FIGURE 6: A BSO-treated mother (TM) variety BioL-212 and its mutant (MuT) rlfL-1 exhibiting leaf and stem necrosis and premature leaf senescence symptoms.

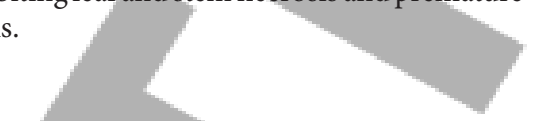

became close to MC value in MuT (Table 2), indicating signs of normalization of mitotic events in MuT plants. Similar situation was encountered in case of phase indices and duration of divisional stages in mutant plants. While PI value was enhanced, MtI, AI, and TI reduced considerably, reaching close to their respective MC values (Table 2). Peak metaphase and anaphase durations enhanced significantly but no significant change was observed for prophase and telophase (data not shown). In TM plants, BSO-exposure induced sharp decline in MI values which were mainly orchestrated through reduction in phase indices and duration of metaphase and anaphase. The results clearly suggested that favorable GSH-redox pool is extremely important in maintaining proper frequency, rate, and proceedings of mitotic events in plant cell and agreed well with earlier studies on Arabidopsis rml 1, rice mill, and BSO-treated genotypes exhibiting huge short-fall in GSH pool [6].

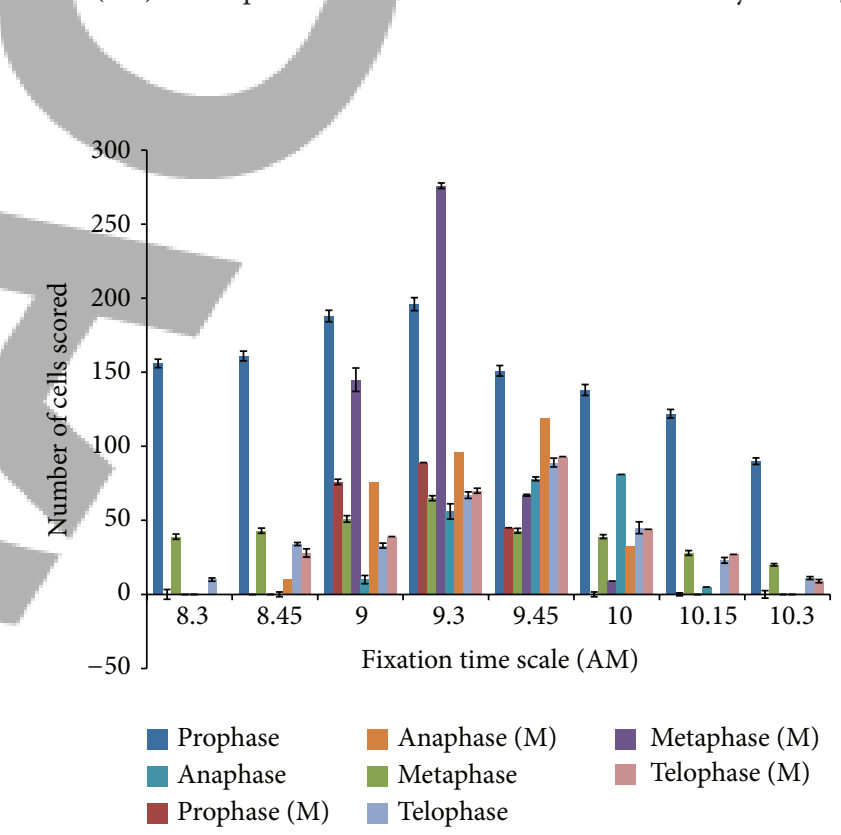

FIGURE 7: Duration of mitotic phases in rlfL-1 mutant (M) and its mother variety BioL-212 in grass pea. Bar followed by error bar represents means \pm SE of at least four replicates.

3.3. Involvement of Cys and GSH Pool and Regulations of Gene Expressions in Controlling rlfL-1 Phenotype. In order to ascertain the remarkable fitness of rlfL-1 mutant despite several cytological abnormalities, roles of thiol cascade mediated by Cys and GSH were investigated. Measurable GSH levels were significantly higher in rolled leaves and fasciated stems of the mutant plants than that in MC plants. However, Cys level in mutant tissues was marginally higher than the MC level (Table 2). The GSSG pool was close to MC plants, leading to very high GSH-redox in the mutant tissues (Table 2). GSH is important in maintaining intracellular redox balance 
and increased GSH level was found to be associated with a proliferative response and is essential for survival of proliferative tissue through rapid cell cycle progression in both plant and animal cells undergoing tumorigenesis [5$7,69]$. In the present investigation, high mitotic activity powered by elevated frequency of dividing cells and rapid turnover during metaphase and anaphase in growing tip of rolled leaf might be the consequences of high GSH-redox, maintaining quite favorable reducing environment for cell divisions. A net increase in the total GSH pool of the dividing cells may also be required to ensure that sufficient GSH is available for distribution between the newly formed cells following mitosis, as explained in proliferating Arabidopsis cells [69]. This might be instrumental in maintaining and originating new fasciated portions in stems and buds of the present rlfL-1 mutant. However, occurrence of high karyomorphological anomalies in $\mathrm{MuC}$ plants despite elevated GSH pool is interesting. GSH is recruited in the nucleus, and in proper redox, it is known to protect nuclear apparatus [69]. Certainly, quick turnover of cell division process and inherent instability of tumor cells led to consistent fault in chromosomal pairing and association which, accompanied by spindle disturbances as manifested by multipolarity, diagonal anaphase, laggard, and so forth in MuC plants, was inherited in the subsequent divisional stages without getting any chance to correct it properly. The importance of GSH in maintaining leaf-rolling and stem as well as bud proliferations in the present rlfL-1 mutant was also evidenced once BSO was added in the medium. BSO is a specific inhibitor of $\gamma$-ECS, the first committed enzyme of GSH-biosynthesis. Measurable GSH level reduced while GSSG pool enhanced significantly in rolled leaves and fasciated stems exposed to $\mathrm{BSO}$, resulting in sharp decline in GSH-redox in proliferated tissues (Table 2). Low GSH-redox severely perturbs ROShomeostasis, tilting the delicate balance in favor of oxidative cellular environment, and triggers series of oxidative damage in plant cell $[2,3]$. GSH is usually recruited by cell during early stage of cell proliferations [69], and any disturbances in its redox state towards oxidative environment may sensitize proliferative tissue towards oxidative stress. Although GSH deficiency leads to severe disturbances in plant phenotypic manifestations and ontogeny $[5-8,13]$, reversals of rolled leaf and fasciated stem in the present case presumably were the consequences of reduced GSH-redox status. Surprisingly enough that despite huge GSH pool in proliferating tissues of the present mutant, BSO-treatment reduced its level in a comparable amount in both proliferating and nonproliferating tissues. In order to ascertain it, a time-course preliminary analysis with $\mathrm{BSO}$ was conducted. The results revealed that GSH level in fasciated tissues and rolled leaf was marginally changed at initial stage of treatment but started to decline from $30 \mathrm{~h}$ onwards and severe depletion was measured at $120 \mathrm{~h}$ (Talukdar, Unpublished). Occurrence of severe necrosis coupled with premature senescence in leaves of the present mutant and in TM plants suggested that depleted endogenous GSH-pool in the proliferating tissues was unable to maintain the cell growth due to substantial loss in pace of mitotic activity. Yet, occurrence of small percentage of leaf rolling and fasciation in BSO-treated mutant at initial treatment period is important. Although there is still no evidence that GSH is synthesized in nucleus of the plant cell, substantial amount of GSH can be recruited by plant nucleus at the expense of the cytosolic GSH pool [69]. As GSH pool within nucleus is highly resistant to BSO treatment, it seems likely that high GSH level was maintained by proliferating tissues for some time which ultimately declined due to inhibition of GSH biosynthesis by BSO and continuous consumption of GSH to meet cellular demands. Remarkably enough, Cys pool was significantly higher in TM plants than MC but markedly reduced to MC level in BSO-treated MuT plants (Table 2).

Enzyme activity and gene expression analysis pointed out upregulations of mRNA transcripts controlling OAS-TL and $\gamma$-ECS activities in rlfL-1 mutant (Figures 8, and 9(a)). No significant change was observed in relative expressions of two LsSAT isoforms (Figures 8, and 9(a)). The enhanced expression of OAS-TL was mainly due to increased abundance of both putative OAS-TLA and OAS-TLC transcripts (Figures 8, and 9(a)). This was concomitant with significant rise in OAS-TL activity in the mutant plants (Table 3), indicating transcriptional regulations of OAS-TL genes in the present grass pea mutants. Similarly, significant upregulations of $\gamma$-ECS transcripts in the mutant steered activity of $\gamma$-ECS enzymes by about 3.5-fold increase over MC level (Table 3). The $\gamma$-ECS is a rate-limiting enzyme and uses Cys as the vital building block of $\gamma$-glutamylcysteine, the precursor of GSH in the chloroplast [1-3]. In nonproliferating cells, high GSH level often regulated $\gamma$-ECS activity through feedback inhibition [2]. However, in the present mutant, stimulated Cys and GSH biosynthesis led to increased GSH accumulation presumably to keep the cells proliferating. Moreover, increased GSH synthesis in proliferating cells would serve to restore the redox potential of the cytosol and thus whole cell redox homeostasis $[5,20]$. Similar role of GSH in progression of cancer was noticed in animal cells [20], although direct effect of Cys metabolisms in maintaining GSH level was not explored. The present study indicated that upstream thiol metabolisms (Cys biosynthesis) may play vital roles in keeping downstream thiol-status favorable to maintain proliferative growth in plant cell. Therefore, without ruling out other possibilities, vigorous consumption of Cys required for GSH biosynthesis might be one of the causes for marginal increase in Cys pool in MuC plants, despite high OAS-TL activity. This concept was further strengthened in BSO-treated mutant and mother plants. Compared to $\mathrm{MuC}, \mathrm{OAS}-\mathrm{TL}$ expressions and enzyme activity were only marginally changed but transcript abundance and activity of $\gamma$-ECS were not observed in MuT plants (Figures 8, and 9(a)). In TM plants, BSO treatment has no effect on OAS-TL gene expressions and activity but like MuT plants $\gamma$-ECS transcript was not detectable at all. The results reaffirmed specific inhibition of $\gamma$-ECS by BSO without any apparent effect on Cys-synthesizing machinery. The nonsignificant change in activity and gene expressions of both isoforms of LSSAT in $\mathrm{MC}, \mathrm{MuC}, \mathrm{MuT}$, and TM plants suggested constitutive expressions of the genes during Cys biosynthesis, and thus upregulations of Cys biosynthesis in the present grass pea mutant were mainly conferred by enhanced transcripts of OAS-TL isoforms. The responsiveness of OAS-TL to changing 
TABLE 3: Activities of $\gamma$-glutamylcysteine synthetase $\left(\gamma\right.$-ECS, $n$ mol $\left.\mathrm{min}^{-1} \mathrm{~g}^{-1} \mathrm{FW}\right)$, serine acetyl transferase (SAT, U mg ${ }^{-1} \mathrm{protein}^{-}, \mathrm{O}^{-}$ acetylserine thiol lyase (OAS-TL, nmol cysteine $\mathrm{min}^{-1} \mathrm{mg}^{-1}$ protein), superoxide dismutase (SOD, $\mathrm{U} \mathrm{min}^{-1} \mathrm{mg}^{-1} \mathrm{protein}^{-1}$ ascorbate peroxidase (APX, $\mu \mathrm{mol}$ ascorbate oxidized $\mathrm{min}^{-1} \mathrm{mg}^{-1}$ protein), glutathione reductase (GR, nmol NADPH oxidized min ${ }^{-1} \mathrm{mg}^{-1} \mathrm{protein}$ ), glutathione-S transferases (GSTs, $\mathrm{U} \mathrm{mg}^{-1}$ protein), and glutathione peroxidase (GPX, nmol NADPH min ${ }^{-1} \mathrm{mg}^{-1}$ (protein)), L-cysteine desulfhydrase (LCD, nmol $\mathrm{H}_{2} \mathrm{~S} \mathrm{~min} \mathrm{mg}^{-1}$ protein), D-cysteine desulfhydrase (DCD, $\mathrm{nmol} \mathrm{H}_{2} \mathrm{~S} \mathrm{~min}^{-1} \mathrm{mg}^{-1}$ protein), hydrogen sulfide level $\left(\mathrm{H}_{2} \mathrm{~S}, \mu \mathrm{mol} \mathrm{g}^{-1} \mathrm{FW}\right)$ and glycolate oxidase (GO, $\mu$ mol glyoxylate $\mathrm{min}^{-1} \mathrm{mg}^{-1}$ protein) $\mathrm{H}_{2} \mathrm{O}_{2}\left(\mu\right.$ mol g $\left.\mathrm{g}^{-1} \mathrm{FW}\right)$, malondialdehyde (MDA, $\left.\mathrm{nmol} \mathrm{g}{ }^{-1} \mathrm{FW}\right)$ in rlfL-1 mutant and its mother variety Biol-212 under untreated and BSO-treated conditions.

\begin{tabular}{|c|c|c|c|c|}
\hline Traits & MC & $\mathrm{MuC}$ & MuT & TM \\
\hline$\gamma$-ECS & $6.8 \pm 1.1^{\mathrm{b}}$ & $23.8 \pm 4.2^{\mathrm{a}}$ & ND & ND \\
\hline SAT & $0.65 \pm 0.08^{\mathrm{a}}$ & $0.69 \pm 0.05^{\mathrm{a}}$ & $0.64 \pm 0.03^{\mathrm{a}}$ & $0.64 \pm 0.07^{\mathrm{a}}$ \\
\hline OAS-TL & $23.6 \pm 1.97^{\mathrm{b}}$ & $70.2 \pm 3.33^{\mathrm{a}}$ & $69.7 \pm 3.12^{\mathrm{a}}$ & $22.5 \pm 1.90^{\mathrm{b}}$ \\
\hline SOD-leaf & $180.3 \pm 9.1^{b}$ & $178.9 \pm 6.3^{\mathrm{b}}$ & $359.7 \pm 10.5^{\mathrm{a}}$ & $356.6 \pm 10.6^{\mathrm{a}}$ \\
\hline SOD-stems & $165.3 \pm 7.3^{b}$ & $170.7 \pm 5.9^{\mathrm{b}}$ & $343.4 \pm 9.5^{\mathrm{a}}$ & $350.8 \pm 11.0^{\mathrm{a}}$ \\
\hline APX-leaf & $131.3 \pm 8.8^{\mathrm{b}}$ & $328.3 \pm 11.2^{\mathrm{a}}$ & $34.56 \pm 2.4^{\mathrm{a}}$ & $35.66 \pm 1.9^{\mathrm{a}}$ \\
\hline APX-stems & $111.5 \pm 6.7^{\mathrm{b}}$ & $282.3 \pm 11.2^{\mathrm{a}}$ & $29.67 \pm 2.8^{c}$ & $30.59 \pm 2.5^{c}$ \\
\hline GR-leaf & $31.2 \pm 2.2^{\mathrm{b}}$ & $131.04 \pm 12.5^{\mathrm{a}}$ & $129.8 \pm 12.3^{\mathrm{a}}$ & $30.9 \pm 2.1^{\mathrm{b}}$ \\
\hline GR-stems & $33.2 \pm 2.2^{\mathrm{b}}$ & $134.07 \pm 10.8^{\mathrm{a}}$ & $130.9 \pm 12.9^{a}$ & $33.9 \pm 2.8^{\mathrm{b}}$ \\
\hline GSTs-leaf & $0.22 \pm 0.08^{\mathrm{b}}$ & $1.21 \pm 2.8^{\mathrm{a}}$ & $0.30 \pm 0.08^{\mathrm{b}}$ & $0.05 \pm 0.008^{c}$ \\
\hline GSTs-stem & $0.25 \pm 0.10^{\mathrm{b}}$ & $1.25 \pm 2.9^{\mathrm{a}}$ & $0.33 \pm 0.07^{\mathrm{b}}$ & $0.06 \pm 0.008^{c}$ \\
\hline GPX-leaf & $7.1 \pm 0.98^{\mathrm{b}}$ & $13.49 \pm 3.3^{\mathrm{a}}$ & $8.99 \pm 0.89^{b}$ & $4.72 \pm 0.77^{\mathrm{c}}$ \\
\hline GPX-stems & $7.8 \pm 0.99^{\mathrm{b}}$ & $12.87 \pm 3.2^{\mathrm{a}}$ & $9.01 \pm 0.90^{\mathrm{b}}$ & $4.69 \pm 0.69^{c}$ \\
\hline LCD-leaf & $20.38 \pm 0.64$ & $11.67 \pm 0.45$ & $46.67 \pm 0.78$ & $19.38 \pm 0.63$ \\
\hline LCD-stems & $17.54 \pm 0.45^{\mathrm{b}}$ & $10.58 \pm 0.39^{c}$ & $37.03 \pm 0.41^{\mathrm{a}}$ & $18.54 \pm 0.41^{\mathrm{b}}$ \\
\hline DCD-leaf & $16.15 \pm 0.63^{\mathrm{b}}$ & $9.87 \pm 0.37^{c}$ & $40.23 \pm 0.69^{\mathrm{a}}$ & $16.03 \pm 0.59^{\mathrm{b}}$ \\
\hline DCD-stems & $13.18 \pm 0.55$ & $7.99 \pm 0.29$ & $28.01 \pm 0.72$ & $13.20 \pm 0.51$ \\
\hline $\mathrm{H}_{2} \mathrm{~S}$ level-leaf & $0.047 \pm 0.003^{b}$ & $0.029 \pm 0.002^{c}$ & $0.087 \pm 0.006^{\mathrm{a}}$ & $0.050 \pm 0.003^{\mathrm{b}}$ \\
\hline $\mathrm{H}_{2} \mathrm{~S}$ level-stems & $0.033 \pm 0.002^{\mathrm{b}}$ & $0.025 \pm 0.001^{c}$ & $0.088 \pm 0.007^{\mathrm{a}}$ & $0.034 \pm 0.002^{\mathrm{b}}$ \\
\hline GO activity-leaf & $0.85 \pm 0.03^{b}$ & $0.76 \pm 0.03^{b}$ & $2.28 \pm 0.09^{\mathrm{a}}$ & $0.83 \pm 0.02^{\mathrm{b}}$ \\
\hline $\mathrm{H}_{2} \mathrm{O}_{2}$-leaf & $3.32 \pm 0.81^{\mathrm{c}}$ & $3.19 \pm 0.62^{c}$ & $21.67 \pm 0.98^{\mathrm{a}}$ & $14.56 \pm 0.34^{\mathrm{b}}$ \\
\hline $\mathrm{H}_{2} \mathrm{O}_{2}$-stem & $3.21 \pm 0.67^{c}$ & $3.05 \pm 0.62^{c}$ & $17.13 \pm 0.54^{\mathrm{a}}$ & $10.44 \pm 0.29^{\mathrm{b}}$ \\
\hline MDA-leaf & $4.23 \pm 0.71^{\mathrm{c}}$ & $4.13 \pm 0.65^{c}$ & $28.78 \pm 0.87^{\mathrm{a}}$ & $16.23 \pm 0.33^{b}$ \\
\hline MDA-stems & $3.99 \pm 0.53^{c}$ & $3.20 \pm 0.44^{\mathrm{c}}$ & $22.56 \pm 0.49^{\mathrm{a}}$ & $14.31 \pm 0.29^{\mathrm{b}}$ \\
\hline EL\%-leaf & $4.04 \pm 0.38^{c}$ & $4.16 \pm 0.38^{c}$ & $27.34 \pm 0.55^{\mathrm{a}}$ & $12.87 \pm 0.22^{\mathrm{b}}$ \\
\hline EL\%-stems & $3.87 \pm 0.29^{c}$ & $4.10 \pm 0.35^{c}$ & $25.58 \pm 0.50^{\mathrm{a}}$ & $12.32 \pm 0.19^{b}$ \\
\hline
\end{tabular}

Data are means \pm SE of at least four replicates. Means followed by same alphabets are not significantly $(P>0.05)$ different at ANOVA followed by Duncan's multiple range test. MC-untreated (no BSO) mother control, MuC-untreated (no BSO), MuT-BSO-treated mutant, and TM-BSO treated mother plant.

cellular and physiological environment has been elucidated in Arabidopsis, cereals, and legumes, experiencing diverse cellular and metabolic alterations during stress $[1,4,15]$. Interestingly, Cys pool was significantly higher in TM plants than MC, MuC, and MuT despite nonsignificant change in SAT and OAS-TL activity and transcript abundance. Contrastingly, OAS-TL activity was much higher in MuT plants; yet Cys pool markedly reduced. The results strongly indicated that Cys is consumed or metabolized by way(s) other than GSH in the present $r l f L-1$ mutant exposed to BSO. Certainly, this has not been operative in TM plants, resulting in Cys overaccumulation.

3.4. Analysis of GSH-Dependent Antioxidant Defense Response and Gene Expressions in rlfL-1 Mutant. The rise of GSH redox pool in $\mathrm{MuC}$ and its substantial fall in the mutant plants upon BSO treatment has cascading effect on antioxidant gene expressions and defense response. Activities of APX, GR,
GSTs, and GPX increased in both leaves and stems of MuC plants by about 2.5-, 4.2-, 5.5-, and 1.9-fold, respectively, over those in the MC plants (Table 3). By contrast, SOD activity was marginally changed in the mutant. The activities of most of the enzymes except LsGST2 isoform were regulated at transcriptional level. Relative gene expressions of LsAPX1, LsAPX2, LsAPX3, LsGr1, LsGr2, LsGST1, and one LsGPX isoform were significantly upregulated in the stems and leaves of the mutant plants (Figure 8). Compared to MC, no significant change in expressions, however, was observed in Cu/ZnSOD I and II and one FeSOD isoform in the mutant (Figures 8, and 9(b)). APX and GR are the two important constituents of AsA-GSH cycle. With several isoforms, APX is the most prolific $\mathrm{H}_{2} \mathrm{O}_{2}$-scavenging machinery within cell $[2,3,38]$. On the other hand, GR has immense significance in maintaining GSH redox by regenerating GSH from its oxidized form GSSG [2,3]. Arabidopsis and Lathyrus sativus L. mutants deficient in GR activities reportedly failed to maintain proper GSH-redox value despite normal $\gamma$-ECS 


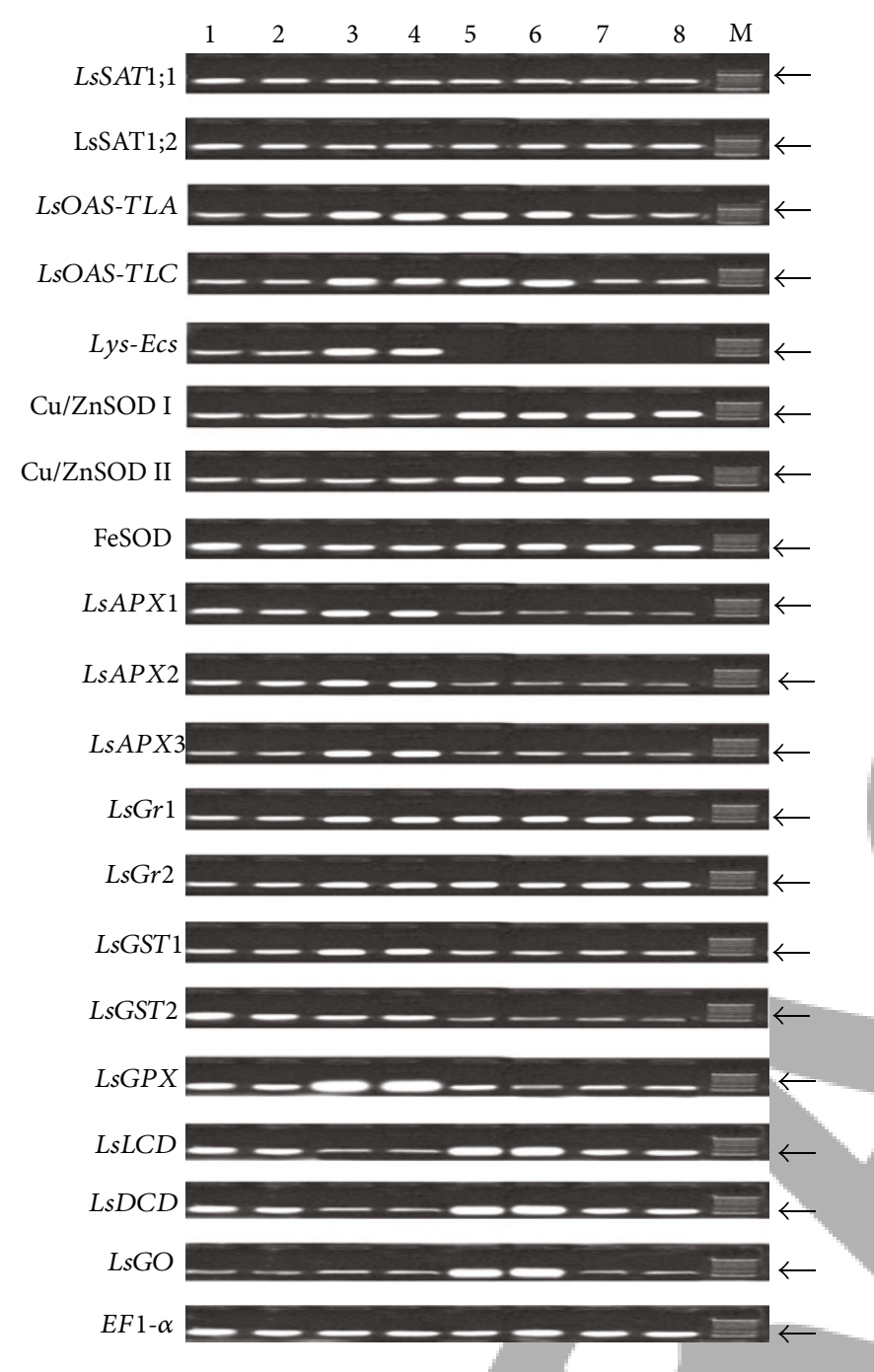

FIGURE 8: mRNA gene expression analysis of Lathyrus sativus (Ls) serine acetyl transferases (SATs) 1;1 and 1;2, O-acetylserine thiol lyase (OAS-TL) A and C, $\gamma$-glutamylcysteine synthetase $(\gamma$-ECS), $\mathrm{Cu} / \mathrm{Zn}$ superoxide dismutase (SOD) I and II, FeSOD, ascorbate peroxidase (APX) 1, 2, and 3, glutathione reductase (Gr) 1 and 2, glutathione $S$-transferase (GST) 1 and 2, glutathione peroxidase (GPX), L-cysteine desulfhydrase (LCD), D-cysteine desulfhydrase (DCD), and glycolate oxidase (GO) isoforms in lanes 1,3,5,7-leaves of mother control (MC), mutant control (MuC), BSO-treated mutant $(\mathrm{MuT})$, and BSO-treated mother (TM), respectively, and in lanes 2,4,6,8-stems of MC, MuC, MuT, and TM plants, respectively, by qRT-PCR, followed by $2 \%$ agarose gel electrophoresis with EF1- $\alpha$ used for cDNA normalization and a $100 \mathrm{bp}$ DNA marker (M) (arrow $300 \mathrm{bp})$.

activities [2, 10]. Upregulations of gene expressions and significantly increased activities of APX and GR enzymes might be instrumental in maintaining $\mathrm{H}_{2} \mathrm{O}_{2}$ and $\mathrm{GSH}$ pool close to $\mathrm{MC}$ level in the mutant. The favorable GSH pool, in turn, galvanized activities of GSTs and GPX, the two prominent enzymes in intracellular detoxification system outside AsA-GSH cycle [12, 13, 41]. GST exclusively requires GSH to perform its diverse functions within cell $[12,13]$. Significant overexpressions of LsGST1 isoform and enzyme activity in rolled leaf and fasciated stem tissues suggested stimulations of GSH-mediated antioxidant defense in the proliferating tissues to contain ROS. Although GPX can use thioredoxins besides GSH as one of its electron donors [41], upregulation of its isoforms boosted antioxidant defense of mutant plants against lipid peroxides in presence of high GSH pool. Increased GPX activity using GSH as substrate was observed in an AsA-deficient mutant of grass pea [70]. In Ctenanthe setosa (Rose.) Eichler (Marantaceae), leaf rolling phenotype was maintained by increased activities of AsAGSH cycle enzymes and capability of the plants to maintain high GSH-redox during cell differentiation [25]. Obviously, GSH-mediated upregulations of ROS-scavenging machinery keep ROS level under tight control in the present mutant plants, managing lipid peroxidation and membrane damage well within the limit (Table 3). The MDA content and EL\% in both stem and leaf tissues of rlfL-1 mutant hovered around the level measured in MC plants (Table 3). High ROS level accompanied by elevated level of MDA and EL\% is the strong indication of oxidative damage in plant cells $[2,4,8,10,11,15$, $45,46,69,70]$. Present results clearly pointed out absence of any such stress in the rlfL-1 mutant.

Blockage of the GSH-mediated detoxification system enhanced the chemosensitivity of several animal tumor cell lines [5]. This enhancement was often engineered through production of excess ROS, targeting proliferated cells $[5,69]$. Generation of oxidative intermediates has been proposed to be a critical event in the process of necrosis and cell death induced by various agents [5]. Consequently, depletion of GSH has been found to either precede the onset of apoptosis or render the cells more sensitive to cell death [5]. In the present study, cellular environment was dramatically changed once BSO was added in the medium. Activity and transcript abundance of SOD isoforms were enhanced by about 2-4-fold over MuC, but those of APX, GST, and GPX enzymes were reduced significantly in MuT plants (Table 3; Figures 8, and 9(b)). While APX activity reduced by about 3.8-fold, GSTs and GPX activity was lowered by nearly 4-fold and 1.5-fold, respectively, in the MuT plants(Table 3). Increased SOD activity was mainly due to enhanced transcriptional expressions of both of its $\mathrm{Cu} / \mathrm{ZnSOD}$ and FeSOD isoforms. Contrastingly, downregulations to the tune of 34-fold in MuT plants triggered fall of APX, GST, and GPX activities to a considerable extent. The differential behavior of LsGST2 transcript expression in relation to enzyme activity suggested possible posttranscriptional regulations of the isoform. More or less similar situation was observed in case of TM plants (Table 3; Figure 8). Increased SOD transcripts indicated generation of excess superoxide radicals in both stems and leaves of MuT and TM plants and response of SOD isoforms to dismutate it. Increased SOD expressions coupled with decreased activity of APX not only engineered over accumulation of $\mathrm{H}_{2} \mathrm{O}_{2}$ but also impeded ability of cells to scavenge it. As $\gamma$-ECS activity was blocked by BSO; the GSH synthesis was severely affected. This along with growing consumption of GSH to quench accumulated ROS consequently led to serious decline in GSH redox state through increased oxidation of GSH to GSSG. No significant change in GR activity and expression of its two isoforms, however, was observed in MuT and TM plants compared to their respective 

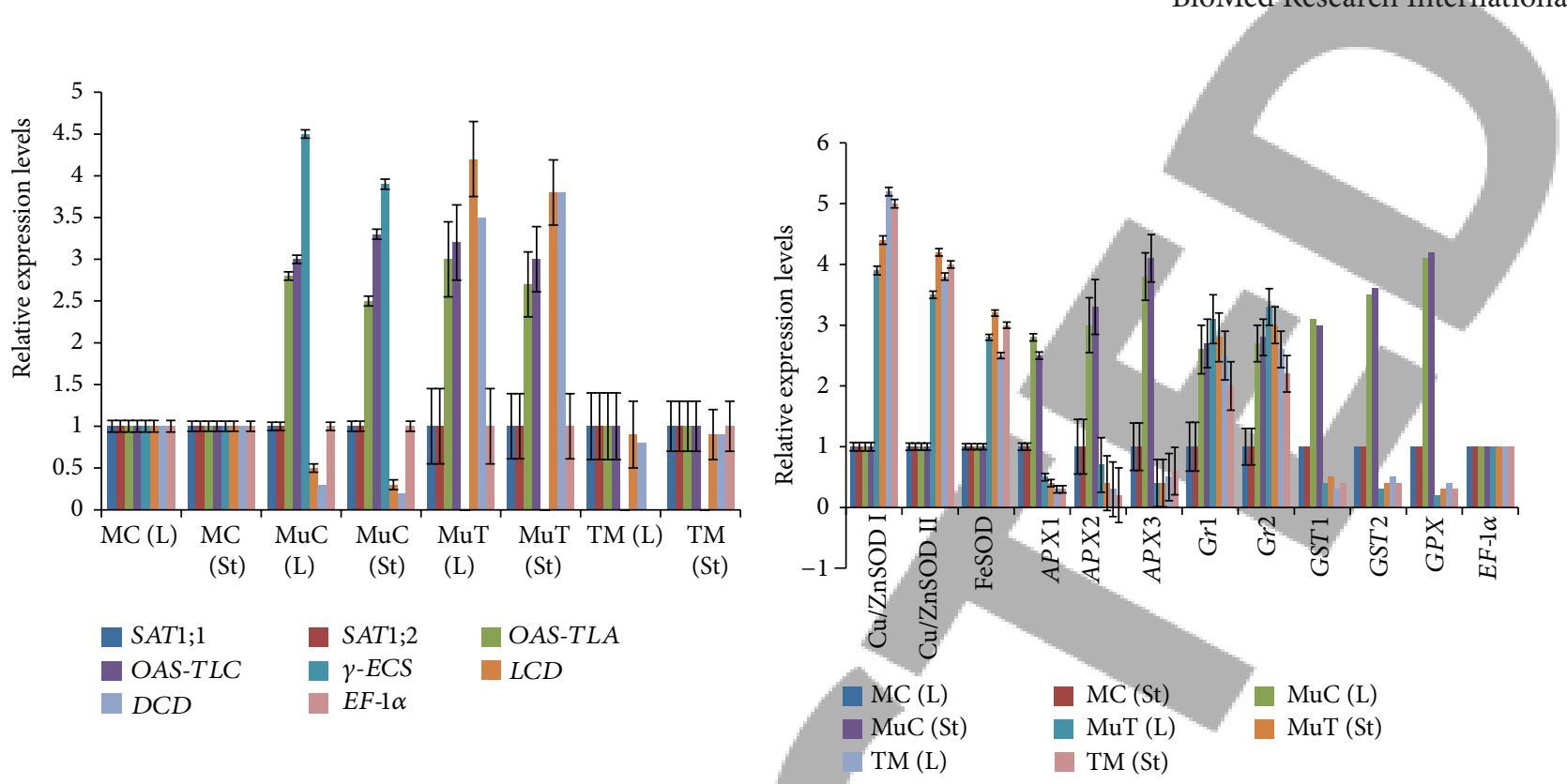

(a)

FIGURE 9: Relative expressions of genes governing mRNA transcripts of Lathyrus sativus L. (a) thiol-metabolizing enzymes and isoforms of SAT, OAS-TL, $\gamma$-ECS, LCD, and DCD; (b) antioxidant defense genes controlling SOD, APX, GR, GST, and GPX isoforms; (c) GO in leaves (L) and stems (St) of MC (mother control), MuC (mutant control), BSO-treated rlfL-1 mutant (MuT), and BSO-treated mother (TM). The mRNA levels were normalized with respect to housekeeping gene EF-1 $\alpha$ and are expressed relative to those of control (MC) value, which were arbitrarily given a value of 1 . Data are means \pm SE of five biological replicates and two technical replicates. Asterisks denote significant changes (upregulation and downregulation) of genes with respect to control values.

controls (Table 3; Figure 8). This was due to the fact that both GR isoforms expressed constitutively in presence or absence of BSO treatment. Furthermore, kinetic studies pointed out that at high GSSG concentrations, the $\mathrm{NaDP}^{+}$, one of the products of GR action, could act as competitive inhibitors of GR $[4,39]$. This might be another reason for nonsignificant change of GR activity between BSO-treated genotypes and their untreated controls in the present case. High GSSG levels led to reduced GSH-redox in MuT and TM plants, hovering even below 0.5 , despite the favorable GR activity. Certainly, maintenance of GSH-redox by GR was insufficient to meet the growing demand for GSH. Low GSH pool seriously jeopardized effectiveness of GST and GPX activities and thereby caused serious impediment in scavenging of toxic cell metabolites and peroxides. The resultant excess accumulation of ROS consequently led to high rate of membrane damage through elevated level of lipid peroxidation in MuT and TM plants (Table 3), marking the onset of oxidative stress. ROS-triggered oxidative damage was manifested by marked decline in plant dry weight and severe necrosis in leaves and stems of both MuT and TM plants. Although traditionally necrotic cell death is considered unprogrammed and 
uncontrolled, recent study in animal and plant cells revealed that its occurrence might be tightly regulated [71], and ROS may play an important role in determining necrosis [71]. In several crop plants and Arabidopsis, oxidative burst led by elevated $\mathrm{H}_{2} \mathrm{O}_{2}$ level caused cell death through necrosis during Agrobacterium-mediated transformations [67]. In the present study, to get more insights regarding involvement of ROS in cell proliferation and necrosis, a pilot experiment was carried out using thiourea (TU, a ROS-scavenger) in the medium with or without BSO. Surprisingly enough, magnitude of leaf rolling and stem fasciation reduced to $60 \%$ of $\mathrm{MuC}$ plants in TU-treated mutant, whereas no necrosis was observed on stem and leaf surface of BSO + TU-treated mutant (Talukdar, unpublished). Primary analysis pointed out drastic reduction of $\mathrm{H}_{2} \mathrm{O}_{2}$ level even below MC plants in rolled leaves (mean $1.12 \pm 0.5$ ) and fasciated stem (mean $0.98 \pm 0.05$ ) of the TUtreated mutant. In $\mathrm{BSO}+$ TU-treated mutant, $\mathrm{H}_{2} \mathrm{O}_{2}$ level also declined from $\mathrm{MuC}$ level but was very close (mean $3.32 \pm 0.8)$ to that measured in MC. It seems likely that along with high GSH level, cells must have certain $\mathrm{H}_{2} \mathrm{O}_{2}$ level to maintain proliferations. Its reduction to $\mathrm{MC}$ level in $\mathrm{BSO}+$ TU-treated mutant was certainly enough to abolish necrosis and cell death. The results indicated that delicate balances of ROS are the determining factor for cell proliferations and necrosis, of course, in the presence of favorable GSHredox to go either way. The dual roles of $\mathrm{H}_{2} \mathrm{O}_{2}$ as an inducer of ROS-mediated oxidative damage as well as cell death and also a signaling molecule to upregulate antioxidant defense to withstand oxidative stress have been studied during plant-pathogen interactions, legume-rhizobium symbiosis, tolerance to abiotic stresses, and in diverse metabolic and cellular events of plant growth and development [9$11,20,37,44]$. Present results confirmed coordinated expressions of antioxidant defense in generating mutant phenotypes and its reversal through necrosis which is sensitive to the redox state of the cell, determined by glutathione pool and the generation of the oxidant $\mathrm{H}_{2} \mathrm{O}_{2}$ within cell $[3,4,9,71]$.

3.5. BSO Treatment Reveals Metabolic Diversion through Cys and Its Cascading Effect on Oxidative Metabolisms of rlfL-1 Mutant. In order to ascertain the possible reasons behind high Cys level in TM plants and its reduction to MC level in MuT plants, we studied desulfuration of Cys predominantly catalyzed by LCD and DCD. Activities of both the enzymes were substantially lower in $\mathrm{MuC}$ plants than MC (Table 3). However, compared to MuC, activities of LCD and DCD were enhanced by about 4.0 -fold and 3.5-fold, respectively, in leaves and stems of MuT plants (Table 3). This enhancement was mainly due to transcriptional overexpressions of $L S L C D$ and $L s D C D$ genes in MuT leaves and stems (Figures 8, and 9(a)). By contrast, no significant change in relation to $\mathrm{MC}$ was observed in transcripts abundance and concomitant enzyme activity in TM plants (Table 3; Figures 8, and 9(a)). As $\mathrm{H}_{2} \mathrm{~S}$ is the major product of LCD and DCD activities, endogenous $\mathrm{H}_{2} \mathrm{~S}$ levels were measured in MuT and TM plants. A 3-3.5-fold increase in $\mathrm{H}_{2} \mathrm{~S}$ content was observed in MuT tissues while no such effect was noticed in TM plants (Table 3). The results clearly pointed out consumption of Cys through upregulations of its degradation pathway in MuT plants in view of the inhibition of GSH biosynthesis, resulting in reduction of Cys content to MC level in MuT plants exposed to BSO. Although Cys is the vital building blocks of proteins and numerous cellular functions, growing evidence indicates that Cys-homeostasis is fundamental for plant metabolisms and unregulated accumulation of free Cys, but not GSH, over a certain threshold can act as powerful prooxidant within plant cell $[16,17]$. Diversion of Cys metabolic route through its sulfuration in the present MuT plants was, therefore, unique and was not observed in TM plants, leading to overaccumulation of Cys but very low $\mathrm{H}_{2} \mathrm{~S}$ content in latter case. $\mathrm{H}_{2} \mathrm{~S}$ can act as a gaseous signaling molecule in promotion of plant growth and stress tolerance $[18,19,43]$, but over certain level it can induce oxidative stress through generation of increased ROS by modulating plant photosynthesis [42]. One of such enzymes is glycolate oxidase (GO) which catalyzes oxidation of glycolate to glyoxylate during photorespiration in higher plants with the production of $\mathrm{H}_{2} \mathrm{O}_{2}[4,42]$. Compared to MuC, GO activity increased by 3 -fold (Table 3 ) while GO transcripts enhanced by about 2.5-3-fold in MuT leaves (Figures 8, and 9(c)). The results suggested that transcriptional upregulations of $G O$ genes conferred increased enzyme activities in BSO-treated mutant plants. No significant change in gene expressions and enzyme activity was observed in TM plants in relation to MC (Table 3; Figures 8, and 9(c)). It is thus noteworthy that a blockage in GSH-synthesizing machinery not only hampered GSH-redox pool but also triggered significant changes in cellular ROS metabolisms through diversions of Cys metabolisms and concomitant induction of $G O$ gene presumably by $\mathrm{H}_{2} \mathrm{~S}$ in $\mathrm{MuT}$ plants. Obviously, high GO activity accompanied with elevated SOD and low APX might be instrumental in accumulation of excess $\mathrm{H}_{2} \mathrm{O}_{2}$ and consequent oxidative damage of membrane in MuT plants. $\mathrm{H}_{2} \mathrm{~S}$-induced ROS-mediated cell death has been reported, although in delayed responses in wheat aleurone cells [72].

3.6. ROS Imaging by CLSM Study. The differential mode of ROS accumulation in leaves and stems of $\mathrm{MC}, \mathrm{MuC}$, $\mathrm{MuT}$, and TM was strongly evidenced by ROS imaging study by CLSM. In MC and MuC, slight red fluorescence due to superoxide radicals localized only in epidermal region was detected (Figures 10(a) and 10(b)). The magnitude of red fluorescence, however, was markedly increased in leaves and stems of MuT and TM plants (Figures 10(c)-10(e)). In leaves of MuT plants, the red fluorescence was detected in high amount in and around vascular regions, sclerenchyma, mesophyll, and epidermis (Figures 10(c) and 10(e)). When the leaf and stem sections were preincubated with $1 \mathrm{mM}$ TMP (a superoxide scavenger), a significant reduction of the fluorescence was observed (Figures $10(\mathrm{f})$ and $10(\mathrm{~g})$ ), thus exhibiting the specificity of DHE for detection and imaging of superoxide radicals in grass pea tissues. For $\mathrm{H}_{2} \mathrm{O}_{2}$ imaging, cross section of MC and MuC leaves and stems incubated with DCF-DA exhibited a bright green fluorescence which was 


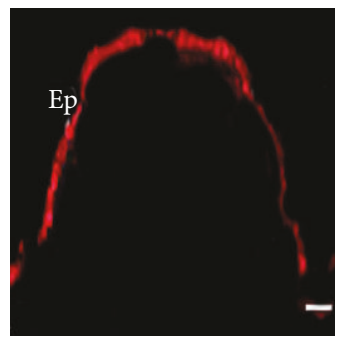

(a)

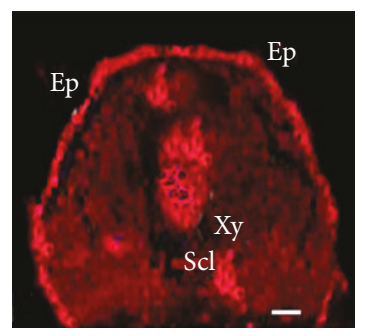

(e)

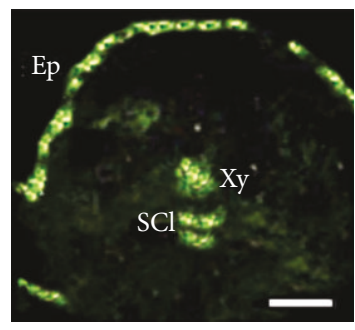

(i)

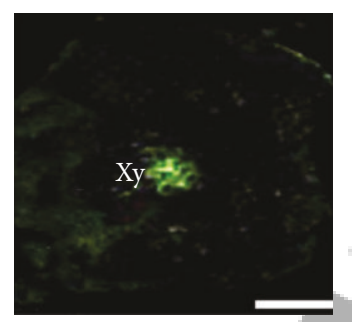

(m)

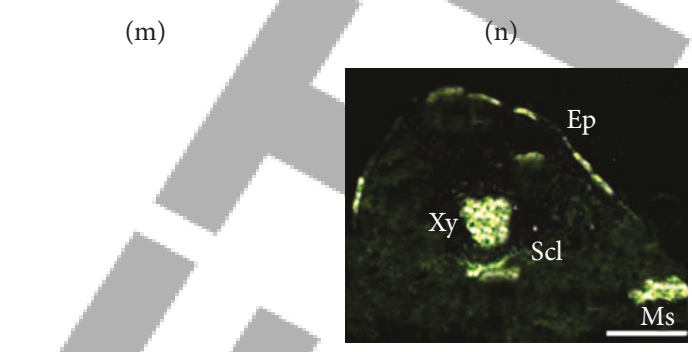

(q)

(f)

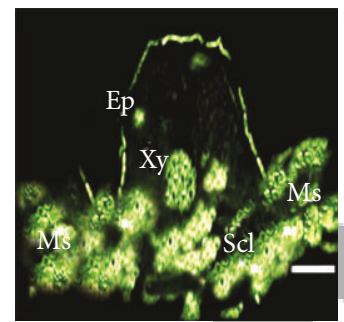

(j)

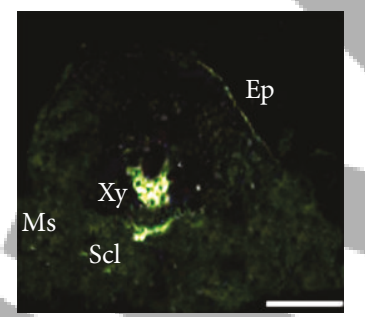

(n)

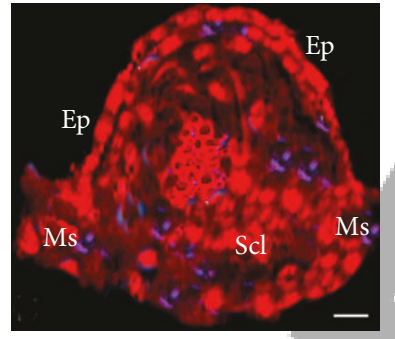

(c)
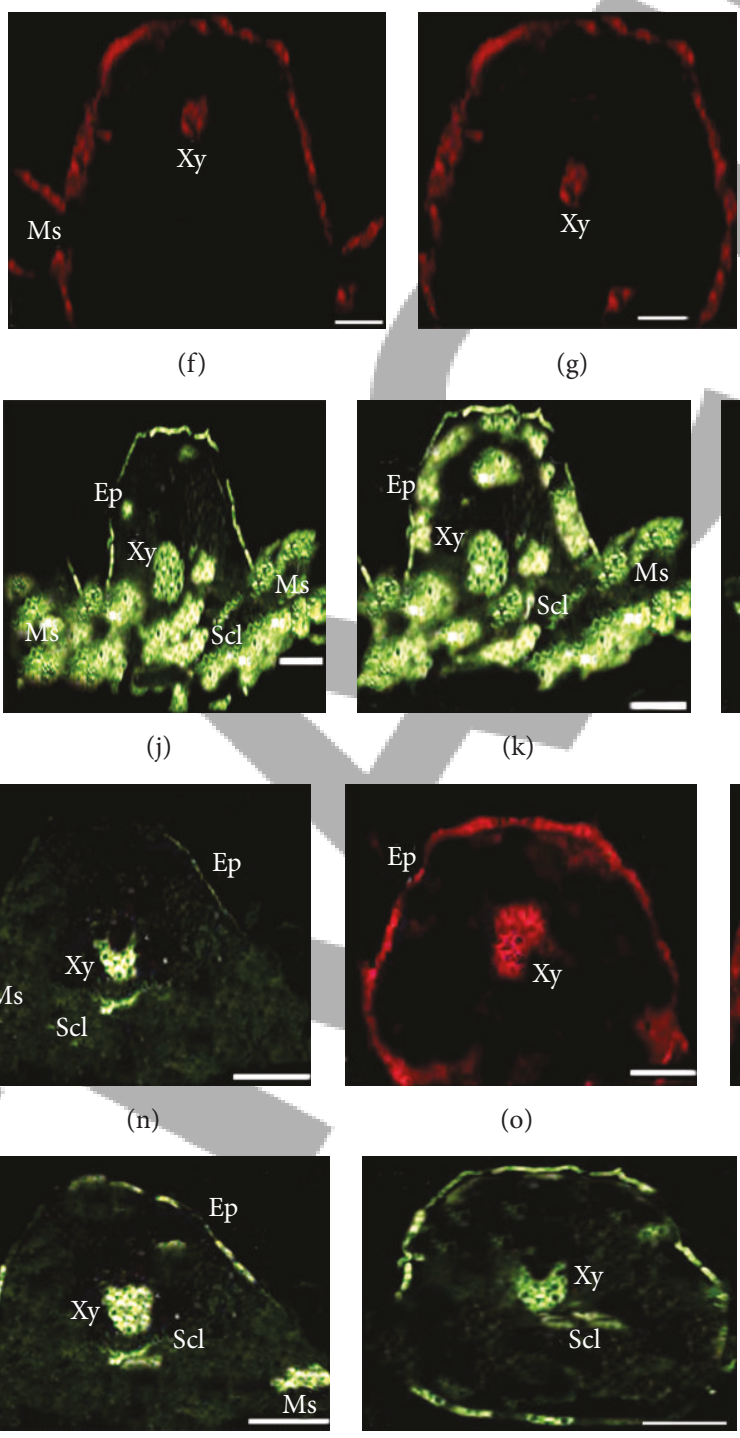

(r)

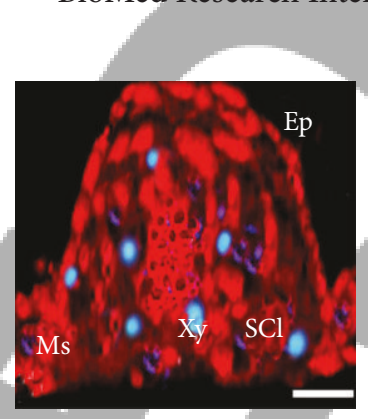

(d)

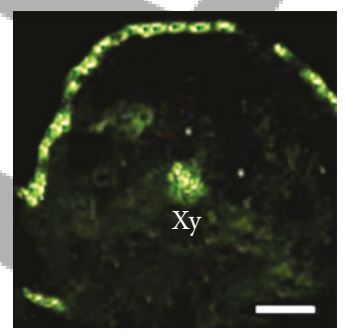

(h)

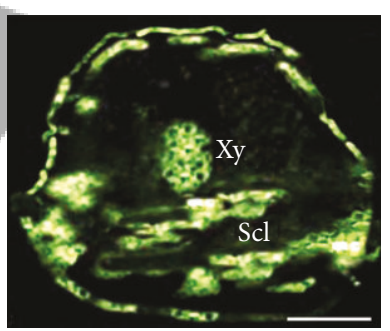

(1)

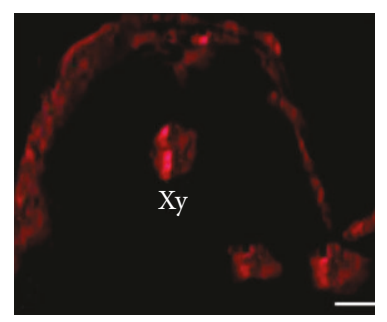

(p)

FIGURE 10: Representative imaging of superoxide radicals and $\mathrm{H}_{2} \mathrm{O}_{2}$ productions in Lathyrus sativus L. leaves by CLSM. Images are developed from several optical sections collected by confocal microscopy showing the autofluorescence (blue; excitation at $633 \mathrm{~nm}$, emission at $680 \mathrm{~nm}$ ) and fluorescence due to DHE and DCF-DA. Superoxide-dependent DHE fluorescence (red) in leaf cross sections from (a) mother control, (b) mutant control, (c) BSO-treated mutant, (d) BSO-treated mother with blue autofluorescence, and (e) stem cross section from BSO-treated mutant; ((f), (g)) for the negative control, leaves (f) and stems (g) of mutant were incubated with 1 mmTMP, a superoxide scavenger; ((h)-(n)) $\mathrm{H}_{2} \mathrm{O}_{2}$-dependent DCF-DA fluorescence (green) in leaf cross sections of (h) mother control, (i) mutant control, (j) BSO-treated mother, (k) BSO-treated mutant, and (l) stem cross section of BSO-treated mutant; ((m), (n)) as a negative control, leaves were incubated with $1 \mathrm{~mm}$ ascorbate (ASC), which acts as a $\mathrm{H}_{2} \mathrm{O}_{2}$ scavenger in BSO-treated (m) mother and (n) treated mutant, (o) stem cross section of stem and (p) leaves of thiourea + BSO-treated mutant with DHE fluorescence (red), (q) thiourea + BSO-treated leaves, and ( $\mathrm{r}$ ) stems of mutant with $\mathrm{H}_{2} \mathrm{O}_{2}$-dependent DCF-DA fluorescence (green). The results are representative of at least three independent experiments. Ep: epidermis; Hp: hypodermis; Ms: mesophyll cells; Scl: sclerenchyma; Xy: xylem vessels. Bars $=50 \mu \mathrm{m}$. 
restricted to only epidermis and xylem regions of vascular tissue and additionally in sclerenchyma region of $\mathrm{MuC}$ leaves (Figures 10(h) and 10(i)). In leaves and stems of MuT and TM plants, the green fluorescence was enhanced markedly in vascular bundles, sclerenchyma, mesophyll regions (leaf), and in epidermis (Figures 10(j)-10(l)). A preincubation with $1 \mathrm{mM}$ ascorbate considerably tamed the florescence The analysis of superoxides and $\mathrm{H}_{2} \mathrm{O}_{2}$ by CLSM showed an enhanced generation of superoxide radicals and $\mathrm{H}_{2} \mathrm{O}_{2}$ /other peroxides and their abundant localizations in leaf and stem tissues of MuT and TM, exposed to BSO. Overproduction of superoxides and $\mathrm{H}_{2} \mathrm{O}_{2}$ was distinctly visible by CLSM study in crop plants $[2,3,37]$. The absence of both red and green fluorescences in mesophyll tissues of present MC and $\mathrm{MuC}$ and their abundant occurrence even in overlapping conditions with tissue autofluorescence (blue) in some cases in leaves of MuT and TM plants suggested involvement of chloroplasts in ROS production in the present materials. Both red and green fluorescences were considerably tamed in plants treated with thiourea (Figures 10(o)-10(r)), a ROSscavenger. The results confirmed that BSO treatment strongly induced ROS generation in both $r l f L-1$ mutant and its mother variety and both superoxide generations and $\mathrm{H}_{2} \mathrm{O}_{2}$ productions are regulated by fine tuning of antioxidant defense in the present rlfL-1 mutant.

\section{Conclusions}

The rlfL-1 mutant exhibited characteristic leaf-rolling and stem as well as bud fasciation in grass pea. Both the phenomena were associated with severe disturbances in chromosomal behavior including origin of aneuploidy and were powered by vigorous mitotic cell divisions, indicating cell proliferations and tolerance to unbalanced genomes. Coordinated overexpressions of vital Cys and GSH-synthesizing genes and upregulations of GSH-dependent antioxidant defense under favorable GSH-redox in MuC leaves and stems contained ROS within MC level, as imaged by CLSM study. Several unique events were detected once BSO was added to the medium. Reversal of mutant phenotypes occurred in association with significant downregulations of GSH-synthesis and concomitant reduction of GSH-redox as well as GSHdependent antioxidant defense, resulting in overaccumulation of ROS and onset of severe necrosis in MuT. These events were accompanied by upregulations of genes involved in Cys-desulfuration, release of $\mathrm{H}_{2} \mathrm{~S}$, and overexpressions of GO in photorespiratory pathway in MuT but not in TM. Presumably, onset of necrosis coupled with premature leaf senescence during BSO-mediated reversal of rolled leaf and stem fasciation in the present mutant involves (1) downregulations of GSH-mediated antioxidant capacity, (2) upregulations of Cys-degrading pathways and induction of more $\mathrm{H}_{2} \mathrm{O}_{2}$ production through $\mathrm{H}_{2} \mathrm{~S}$, and (3) ROS-mediated onset of cell death via necrosis. Results indicated that high GSHredox pool is vital in maintaining leaf-rolling and fasciation and ROS-mediated cell death through diversion of excess Cys-pool to $\mathrm{H}_{2} \mathrm{~S}$ production during reversal of the mutant traits. Occurrence of multiple nucleoli per cell, aneuploidy, and susceptibility to necrosis strongly suggested cancerous nature of the present mutant traits. Present results revealed intricate relationships between cell biological parameters and events controlled by thiol-redox particularly Cys and GSH in proliferating plant cells and can be utilized in future research regarding ROS-signaling in plant cell proliferation through $\mathrm{H}_{2} \mathrm{O}_{2}-\mathrm{H}_{2} \mathrm{~S}$ relationships and concomitant cellular and metabolic responses.

\section{Conflict of Interests}

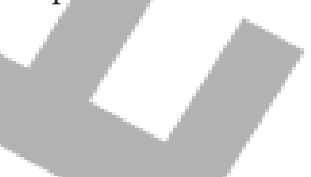

The authors declare that there is no conflict of interests regarding the publication of this paper.

\section{References}

[1] S. Kopriva, S. G. Mugford, P. Baraniecka, B. R. Lee, C. A. Matthewman, and A. Koprivova, "Control of sulfur partitioning between primary and secondary metabolism in Arabidopsis," Frontiers in Plant Science, vol. 3, pp. 1-9, 2012.

[2] C. H. Foyer and G. Noctor, "Ascorbate and glutathione: the heart of the redox hub," Plant Physiology, vol. 155, no. 1, pp. 2-18, 2011.

[3] G. Noctor, A. Mhamdi, G. Queval, and C. H. Foyer, "Regulating the redox gatekeeper: vacuolar sequestration puts glutathione disulfide in its place," Plant Physiology, vol. 163, pp. 665-671, 2013.

[4] M. S. Rahantaniaina, A. Tuzet, A. Mhamdi, and G. Noctor, "Missing links in understanding redox signaling via thiol/disulfide modulation: how is glutathione oxidized in plants?" Frontiers in Plant Science, vol. 4, article 477, 2013.

[5] N. Traverso, R. Ricciarelli, M. Nitti et al., "Role of glutathione in cancer progression and chemoresistance," Oxidative Medicine and Cellular Longevity, vol. 2013, Article ID 972913, 10 pages, 2013.

[6] T. Vernoux, R. C. Wilson, K. A. Seeley et al., "The ROOT MERISTEMLESS1/CADMIUM SENSITIVE2 gene defines a glutathione-dependent pathway involved in initiation and maintenance of cell division during postembryonic root development," Plant Cell, vol. 12, no. 1, pp. 97-109, 2000.

[7] J. Häsler, J. Wüest, T. Gaspar, and M. Crèvecoeur, "Long term in vitro-cultured plant cells show typical neoplastic features at the cytological level," Biology of the Cell, vol. 95, no. 6, pp. 357-364, 2003.

[8] D. Talukdar, "Balanced hydrogen peroxide metabolism is central in controlling $\mathrm{NaCl}$-induced oxidative stress in medicinal legume, fenugreek (Trigonella foenum-graecum L.)," Biochemistry \& Molecular Biology, vol. 1, no. 2, pp. 34-43, 2013.

[9] S. J. Neill, R. Desikan, A. Clarke, R. D. Hurst, and J. T. Hancock, "Hydrogen peroxide and nitric oxide as signalling molecules in plants," Journal of Experimental Botany, vol. 53, no. 372, pp. 1237-1247, 2002.

[10] D. Talukdar, "Arsenic-induced changes in growth and antioxidant metabolism of fenugreek," Russian Journal of Plant Physiology, vol. 60, no. 5, pp. 652-660, 2013.

[11] D. Talukdar, "Exogenous calcium alleviates the impact of cadmium-induced oxidative stress in Lens culinaris Medic. seedlings through modulation of antioxidant enzyme activities," Journal of Crop Science and Biotechnology, vol. 15, no. 4, pp. 325334, 2013. 
[12] D. P. Dixon and R. Edwards, "Selective binding of glutathione conjugates of fatty acid derivatives by plant glutathione transferases," Journal of Biological Chemistry, vol. 284, no. 32, pp. 21249-21256, 2009.

[13] E. Laborde, "Glutathione transferases as mediators of signaling pathways involved in cell proliferation and cell death," Cell Death and Differentiation, vol. 17, no. 9, pp. 1373-1380, 2010.

[14] H. Takahashi, S. Kopriva, M. Giordano, K. Saito, and R. Hell, "Sulfur assimilation in photosynthetic organisms: molecular functions and regulations of transporters and assimilatory enzymes," Annual Review of Plant Biology, vol. 62, pp. 157-184, 2011.

[15] D. Talukdar and T. Talukdar, "Coordinated response of sulfate transport, cysteine biosynthesis and glutathione-mediated antioxidant defense in lentil (Lens culinaris Medik.) genotypes exposed to arsenic," Protoplasma, 2014.

[16] S. Park and J. A. Imlay, "High levels of intracellular cysteine promote oxidative DNA damage by driving the Fenton reaction," Journal of Bacteriology, vol. 185, no. 6, pp. 1942-1950, 2003.

[17] S. Krueger, A. Niehl, M. C. Lopez Martin et al., "Analysis of cytosolic and plastidic serine acetyltransferase mutants and subcellular metabolite distributions suggests interplay of the cellular compartments for cysteine biosynthesis in Arabidopsis," Plant, Cell and Environment, vol. 32, no. 4, pp. 349-367, 2009.

[18] C. Álvarez, L. Calo, L. C. Romero, I. García, and C. Gotor, "An O-Acetylserine(thiol)lyase homolog with 1-Cysteine desulfhydrase activity regulates cysteine homeostasis in arabidopsis," Plant Physiology, vol. 152, no. 2, pp. 656-669, 2010.

[19] J. Chen, F.-H. Wu, W.-H. Wang et al., "Hydrogen sulphide enhances photosynthesis through promoting chloroplast biogenesis, photosynthetic enzyme expression, and thiol redox modification in Spinacia oleracea seedlings," Journal of Experimental Botany, vol. 62, no. 13, pp. 4481-4493, 2011.

[20] J. A. Traverso, A. Pulido, M. I. Rodríguez-García, and J. D. Alché, "Thiol-based redox regulation in sexual plant reproduction: new insights and perspectives," Frontiers in Plant Science, vol. 4, article 465, 2013.

[21] G. T. S. Beemster and T. I. Baskin, "Analysis of cell division and elongation underlying the developmental acceleration of root growth in Arabidopsis thaliana," Plant Physiology, vol. 116, no. 4, pp. 1515-1526, 1998.

[22] L.-P. Zou, X.-H. Sun, Z.-G. Zhang et al., "Leaf rolling controlled by the homeodomain leucine zipper class IV gene roc5 in rice," Plant Physiology, vol. 156, no. 3, pp. 1589-1602, 2011.

[23] L. Williams and J. C. Fletcher, "Stem cell regulation in the Arabidopsis shoot apical meristem," Current Opinion in Plant Biology, vol. 8, no. 6, pp. 582-586, 2005.

[24] F. Taguchi-Shiobara, Z. Yuan, S. Hake, and D. Jackson, “The fasciated ear 2 gene encodes a leucine-rich repeat receptor-like protein that regulates shoot meristem proliferation in maize," Genes and Development, vol. 15, no. 20, pp. 2755-2766, 2001.

[25] N. Saruhan, R. Terzi, A. Saglam, and A. Kadioglu, "The relationship between leaf rolling and ascorbate-glutathione cycle enzymes in apoplastic and symplastic areas of Ctenanthe setosa subjected to drought stress," Biological Research, vol. 42, no. 3, pp. 315-326, 2009.

[26] D. Talukdar, "Cytogenetic characterization of seven different primary tetrasomics in grass pea (Lathyrus sativus L.)," Caryologia, vol. 61, no. 4, pp. 402-410, 2008.

[27] M. C. Vaz Patto, B. Skiba, E. C. K. Pang, S. J. Ochatt, F. Lambein, and D. Rubiales, "Lathyrus improvement for resistance against biotic and abiotic stresses: from classical breeding to marker assisted selection," Euphytica, vol. 147, no. 1-2, pp. 133-147, 2006.

[28] D. Talukdar, "Flavonoid-deficient mutants in grass pea (Lathyrus sativus L.): genetic control, linkage relationships, and mapping with aconitase and $S$ nitrosoglutathione reductase isozyme loci," The Scientific World Journal, vol. 2012, Article ID 345983, 11 pages, 2012.

[29] O. W. Griffith, "Glutathione and glutathione disulfide," in Methods of Enzymatic Analysis, H. U. Bergmeyer, Ed., pp. 521529, Verlagsgesellschaft, Weinheim, Germany, 1985.

[30] M. M. Bradford, "A rapid and sensitive method for the quantitation of microgram quantities of protein utilizing the principle of protein dye binding," Analytical Biochemistry, vol. 72, no. 1-2, pp. 248-254, 1976.

[31] A. Blaszczyk, L. Sirko, M. J. Hawkesford, and A. Sirko, "Biochemical analysis of transgenic tobacco lines producing bacterial serine acetyltransferase," Plant Science, vol. 162, no. 4, pp. 589-597, 2002.

[32] K. Saito, M. Kurosawa, K. Tatsuguchi, Y. Takagi, and I. Murakoshi, "Modulation of cysteine biosynthesis in chloroplasts of transgenic tobacco overexpressing cysteine synthase [O-acetylserine(thiol)-lyase]," Plant Physiology, vol. 106, no. 3, pp. 887-895, 1994.

[33] M. K. Gaitonde, "A spectrophotometric method for the direct determination of cysteine in the presence of other naturally occurring amino acids," Biochemical Journal, vol. 104, no. 2, pp. 627-633, 1967.

[34] G. F. Seelig and A. Meister, " $\gamma$-Glutamylcysteine synthetase. Interactions of an essential sulfhydryl group," Journal of Biological Chemistry, vol. 259, no. 6, pp. 3534-3538, 1984.

[35] E. Bloem, A. Riemenschneider, J. Volker et al., "Sulphur supply and infection with Pyrenopeziza brassicae influence L-cysteine desulphydrase activity in Brassica napus L," Journal of Experimental Botany, vol. 55, no. 406, pp. 2305-2312, 2004.

[36] W. F. Beyer Jr. and I. Fridovich, "Assaying for superoxide dismutase activity: some large consequences of minor changes in conditions," Analytical Biochemistry, vol. 161, no. 2, pp. 559566, 1987.

[37] D. Talukdar and T. Talukdar, "Superoxide-dismutase deficient mutants in common beans (Phaseolus vulgaris L.): genetic control, differential expressions of isozymes, and sensitivity to arsenic," BioMed Research International, vol. 2013, Article ID 782450, 11 pages, 2013.

[38] Y. Nakano and K. Asada, "Hydrogen peroxide is scavenged by ascorbate-specific peroxidase in spinach chloroplasts," Plant and Cell Physiology, vol. 22, no. 5, pp. 867-880, 1981.

[39] I. Carlberg and B. Mannervik, "Glutathione reductase," in Methods in Enzymology, M. Alton, Ed., pp. 484-490, Academic, San Diego, Calif, USA, 1985.

[40] L. Z.-S. Li Ze-Sheng, Z. R.-G. Zhen Rui-Guang, and P. A. Rea, "1-Chloro-2,4-dinitrobenzeene-elicited increase in vacuolar glutathione-S-conjugate transport activity," Plant Physiology, vol. 109, no. 1, pp. 177-185, 1995.

[41] R. Edwards, "Characterization of glutathione transferases and glutathione peroxidases in pea (Pisum sativum)," Physiologia Plantarum, vol. 98, pp. 594-604, 1996.

[42] A. L. Baker and N. E. Tolbert, "Glycolate oxidase (ferredoxincontaining form)," Methods in Enzymology, vol. 9, pp. 338-342, 1966.

[43] J. Sekiya, A. Schmidt, L. G. Wilson, and P. Filner, "Emission of hydrogen sulfide by leaf tissue in response to L-cysteine," Plant Physiology, vol. 70, pp. 430-436, 1982. 
[44] C.-Q. Wang, M. Chen, and B.-S. Wang, "Betacyanin accumulation in the leaves of $\mathrm{C} 3$ halophyte Suaeda salsa $\mathrm{L}$. is induced by watering roots with $\mathrm{H}_{2} \mathrm{O}_{2}$," Plant Science, vol. 172, no. 1, pp. 1-7, 2007.

[45] D. Talukdar, "Arsenic-induced oxidative stress in the common bean legume, Phaseolus vulgaris L. seedlings and its amelioration by exogenous nitric oxide," Physiology and Molecular Biology of Plants, vol. 19, no. 1, pp. 69-79, 2013.

[46] E. Aksoy, Effect of drought and salt stresses on the gene expression levels of antioxidant enzymes in lentil (Lens culinaris M.) seedlings [M.S. thesis], The Graduate School of Natural and Applied Sciences, Middle East Technical University, Ankara, Turkey, 2008.

[47] S. Han and D. Kim, "AtRTPrimer: database for Arabidopsis genome-wide homogeneous and specific RT-PCR primerpairs," BMC Bioinformatics, vol. 7, article 179, 2006.

[48] K. J. Livak and T. D. Schmittgen, "Analysis of relative gene expression data using real-time quantitative PCR and the $2^{-\triangle \Delta C T}$ method," Methods, vol. 25, no. 4, pp. 402-408, 2001.

[49] D. Talukdar, "Fluorescent-banded karyotype analysis and identification of chromosomes in three improved Indian varieties of grass pea (Lathyrus sativus L.)," Chromosome Science, vol. 13, pp. 3-10, 2010.

[50] A. M. A. Matias and I. K. C. Fontanilla, "Optimizing the utility of Allium cepa L. var. aggregatum (sibuyas Tagalog) for the Allium Test by elucidating its mitotic periodicity and rhythmicity under varying light conditions," Science Diliman, vol. 23, no. 1, pp. 43-51, 2011.

[51] D. Talukdar and A. K. Biswas, "Seven different primary trisomics in grass pea (Lathyrus sativus L.). I. Cytogenetic characterisation," Cytologia, vol. 72, no. 4, pp. 385-396, 2007.

[52] G. E. Sarieva, S. S. Kenzhebaeva, and H. K. Lichtenthaler, "Adaptation potential of photosynthesis in wheat cultivars with a capability of leaf rolling under high temperature conditions," Russian Journal of Plant Physiology, vol.57, no. 1, pp. 28-36, 2010.

[53] R. Turgut and A. Kadioglu, "The effect of drought, temperature and irradiation on leaf rolling in Ctenanthe setosa," Biologia Plantarum, vol. 41, no. 4, pp. 629-633, 1998.

[54] A. Kadioglu and R. Terzi, "A dehydration avoidance mechanism: leaf rolling," Botanical Review, vol. 73, no. 4, pp. 290-302, 2007.

[55] A. Saglam, A. Kadioglu, R. Terzi, and N. Saruhan, "Physiological changes in them in post-stress emerging Ctenanthe setosa plants under drought conditions," Russian Journal of Plant Physiology, vol. 55, no. 1, pp. 48-53, 2008.

[56] D. Talukdar, "Recent progress on genetic analysis of novel mutants and aneuploid research in grass pea (Lathyrus sativus L.)," African Journal of Agricultural Research, vol. 4, no. 13, pp. 1549-1559, 2009.

[57] V. N. Waghmare, D. N. Waghmare, and R. B. Mehra, "An induced fasciated mutant in grass pea (Lathyrus sativus L.)," Indian Journal of Genetics and Plant Breeding, vol. 61, pp. 155157, 2001.

[58] S. Srinivasan, P. M. Gaur, and B. V. Rao, "Allelic relationship between spontaneous and induced mutant genes for stem fasciation in chickpea," Plant Breeding, vol. 127, no. 3, pp. 319$321,2008$.

[59] E. Yamamoto, H. C. Karakaya, and H. T. Knap, "Molecular characterization of two soybean homologs of Arabidopsis thaliana CLAVATA1 from the wild type and fasciation mutant," Biochimica et Biophysica Acta-Gene Structure and Expression, vol. 1491, no. 1-3, pp. 333-340, 2000.
[60] C. Toker, S. Shyam Yadav, and I. S. Solanki, "Lentil," in Mutation Breeding, S. S. Yadav, D. L. McNeil, and P. C. Stevenson, Eds., pp. 209-224, Springer, Dordrecht, The Netherlands.

[61] M. R. Lucas, B. L. Huynh, V. P. da Silva et al., "Association studies and legume synteny reveal haplotypes determining seed size in Vigna unguiculata," Frontiers in Plant Science, vol. 4, article 95, 2013.

[62] M. Niizeki and Z. Lu, "Somaclonal variation as a tool for plant breeding and genetics," Bulletin of Faculty of Agriculture \& Life Sciences, Hirosaki University, no. 6, pp. 1-17, 2003.

[63] E. M. Torres, N. Dephoure, A. Panneerselvam et al., "Identification of aneuploidy-tolerating mutations," Cell, vol. 143, no. 1, pp. 71-83, 2010.

[64] J. M. Sheltzer, E. M. Torres, M. J. Dunhamc, and A. Amon, "Transcriptional consequences of aneuploidy," Proceedings of the National Academy of Sciences of the United States of America , vol. 109, no. 31, pp. 12644-12649, 2012.

[65] B. Cetin and D. W. Cleveland, "How to survive aneuploidy," Cell, vol. 143, no. 1, pp. 27-29, 2010.

[66] C.-W. Lee, M. Efetova, J. C. Engelmann et al., “Agrobacterium tumefaciens promotes tumor induction by modulating pathogen defense in arabidopsis thaliana," Plant Cell, vol. 21, no. 9, pp. 2948-2962, 2009.

[67] D. D. Kuta and L. Tripathi, "Agrobacterium-induced hypersensitive necrotic reaction in plant cells: a resistance response against Agrobacterium-mediated DNA transfer," African Journal of Biotechnology, vol. 4, no. 8, pp. 752-757, 2005.

[68] K. Komatsu, M. Hashimoto, J. Ozeki et al., "Viral-Induced systemic necrosis in plants involves both programmed cell death and the inhibition of viral multiplication, which are regulated by independent pathways," Molecular Plant-Microbe Interactions, vol. 23, no. 3, pp. 283-293, 2010.

[69] P. D. Vivancos, Y. Dong, K. Ziegler et al., "Recruitment of glutathione into the nucleus during cell proliferation adjusts whole-cell redox homeostasis in Arabidopsis thaliana and lowers the oxidative defence shield," The Plant Journal, vol. 64, no. 5, pp. 825-838, 2010.

[70] D. Talukdar, "Ascorbate deficient semi-dwarf asfL1 mutant of Lathyrus sativus exhibits alterations in antioxidant defense," Biologia Plantarum, vol. 56, no. 4, pp. 675-682, 2012.

[71] P. Golstein and G. Kroemer, "Cell death by necrosis: towards a molecular definition," Trends in Biochemical Sciences, vol. 32, no. 1, pp. 37-43, 2007.

[72] Y. Xie, C. Zhang, D. Lai et al., "Hydrogen sulfide delays GAtriggered programmed cell death in wheat aleurone layers by the modulation of glutathione homeostasis and heme oxygenase-1 expression," Journal of Plant Physiology, vol. 171, no. 2, pp. 53-62, 2014. 